\title{
Neuroprotection in Parkinson's Disease: A Systematic Review of the Preclinical Data
}

\author{
H. Douna ${ }^{1, \S}$, B.M. Bavelaar ${ }^{1,}$, H. Pellikaan ${ }^{2}$, B. Olivier ${ }^{1}$ and T. Pieters ${ }^{*}, 1,3$ \\ ${ }^{I}$ Utrecht Institute for Pharmaceutical Sciences (UIPS), Utrecht University, The Netherlands \\ ${ }^{2}$ Next Step Pharma, Utrecht, The Netherlands \\ ${ }^{3}$ VU Medical Centre, Amsterdam, The Netherlands
}

\begin{abstract}
Aim: This study aimed to systematically review the preclinical data of neuroprotective agents for Parkinson's disease (PD) to support the translation of these compounds.

Methods: The study consisted of two phases. In phase I, Pubmed and Scopus were systematically searched for neuroprotective agents for PD. In phase II, a systematic search was conducted for each substance identified in phase I. Articles were included if they used MPTP, 6-OHDA, rotenone or paraquat injury models.

Results: Phase I led to the identification of 168 putative neuroprotective agents. Eventually ten compounds were included: melatonin, estrogen, nicotine, caffeine, riluzole, curcumin, coenzyme Q10, aspirin, EGCG and resveratrol. Phase II revealed 113 experimental studies and three reviews.

Conclusion: This study clearly depicts the preclinical data of ten promising neuroprotective agents. While some of these compounds have already been tested in clinical use, none of them was studied in an appropriately designed trial to determine a neuroprotective effect. In expectation of qualitatively improved neuroprotection trials, the data from this study provide a firm foundation for future research.
\end{abstract}

Keywords: Aspirin, caffeine, coenzyme Q10, curcumin, EGCG, estrogen, melatonin, neuroprotection, neuroprotective agents, nicotine, Parkinson's disease, resveratrol, riluzole.

\section{INTRODUCTION}

Parkinson's disease (PD) is a progressive disease that damages neurons in specific dopaminergic brain areas, causing debilitating symptoms, such as resting tremor, rigidity and bradykinesia [1]. Currently, levodopa is widely prescribed as the first-line treatment for PD. Although levodopa is highly effective as a symptomatic treatment, it is incapable of providing the long-term protection that is needed to impair the onset or progress of the disease [2]. As a result, in the more advanced stages of this disease, patients develop motor complications that are not manageable with current treatments. Moreover, the cognitive and autonomic functions of patients become increasingly impaired during the progression of PD [3]. These non-motor complications seriously affect patients' quality of life and are disabling in everyday life. Although the symptoms are serious, the onset of these complications is slow. In addition, it is estimated that there is a six-year time frame from the onset of neuronal cell loss and the emergence of clinical dysfunction [4]. This provides a window for disease-modifying treatments to prevent or delay the ongoing process of neurodegeneration. Since current treatments are unable to meet these

*Address correspondence to this author at the Department of Pharmacoepidemiology and Clinical Pharmacology, Faculty of Science, Utrecht University, Postbox 800 82, 3508 TB Utrecht, The Netherlands; Tel: +31302537324; E-mail: t.pieters@uu.nl

${ }^{\S}$ Both authors contributed equally. requirements, it is clear that there is an urgent need for novel neuroprotective options $[2,5]$.

During the last decade, researchers have shown an increased interest in neuroprotection, resulting in a large volume of published studies investigating neuroprotective or disease-modifying agents. This emphasis has raised high expectations for novel neuroprotective therapeutic options for PD that until now have not been met [6]. However, this does not mean that all this research has not delivered results, rather, the high expectations have clouded gradual advancements [7]. Although disease-modifying therapies have not yet found their way to clinical practice, a substantial number of compounds have been identified as neuroprotective in preclinical studies. Since most physicians rarely access or appraise scientific evidence directly from research results [8], most neurologists have overlooked preclinical improvements, resulting in lowered expectations and misplaced doubts about neuroprotection.

The fact that only a limited number of compounds have been tested in clinical trials is due to several reasons-the most prominent is the limitations in standard clinical trials [5]. Since it is not possible to measure the number of dopaminergic neurons in vivo, most clinical trials use surrogate endpoints such as clinical ratings. The main difficulty with such endpoints is that it is nearly impossible to identify the difference between symptomatic and neuroprotective effects [5]. Therefore, new study designs have been recently developed, such as the delayed-start 
design. In theory, these designs should be able to help differentiate symptomatic from neuroprotective effects of putative neuroprotective agents [5]. Furthermore, novel brain imaging techniques and biomarkers that monitor the loss of dopaminergic neurons will help to improve the quality of neuroprotective clinical trials [7,9]. It is therefore reasonable to expect an increase in higher-quality neuroprotective trials in the near future $[7,10,11]$. Since the field of neuroprotection is wide, public reporting and data mining will enhance this goal [7]. It is thus important that the extensive literature is presented in a systematic and clarifying way.

The aim of this study is to systematically review the preclinical data of neuroprotective agents to support the translation of these compounds from the bench to the bedside.

\section{METHODS}

Given the abundance of published studies of neuroprotection, we covered the field in both a systematic and selective manner. We chose a review strategy similar to the one used by Ravina et al., [12] and Kwon et al., [13] to search for neuroprotective agents for PD and spinal cord injury, respectively. These studies consisted of two phases; the initial step was the identification of the most promising neuroprotective agents.

In phase I, we performed a Pubmed and Scopus search for "neuroprotective agents AND Parkinson's Disease". The abstracts and titles were screened for relevant compounds, which were then assessed by the adjusted criteria developed by the Committee to Identify Neuroprotective Agents in Parkinson's (CINAPS) to identify the most potential agents [12]. Namely:

\section{- Safety and tolerability}

Compounds were recognized as safe when they were already registered as medicines or supplements, listed in the Generally Recognized as Safe (GRAS) database or found to be safe in clinical trials.

- A scientific rationale This includes consistency of preclinical data and a credible mechanism of action.

- Evidence for neuroprotection or indication of benefit

This consists of positive preclinical data in vertebrate animals and data from human trials or epidemiological studies that suggest an association between the agent and a decreased risk of PD.

Moreover, since we aim to identify compounds that could be used in trials in the near future, we only included agents, which are already available for use in humans. This implicates that pipeline products were excluded, as these compounds are not freely available and are still under development. In addition, the majority of pharmaceutical companies only selectively publishes results for pipeline products, which hinders the comprehensive evaluation of these compounds. Another group of substances that was excluded were those that are currently prescribed for PD, such as dopamine receptor agonists or MAO-B inhibitors. Like Ravina et al., [12], when multiple compounds from the same class were identified, we chose the most promising one for detailed evaluation.

Following compound identification in phase I, we performed a systematic literature review in phase II for each therapy in Pubmed and Scopus, using the "agent name" AND "Parkinson OR parkinsonism*" AND "neuroprotection OR neuroprotective OR disease-modifying" as search strings (date: 19-01-2011). We then applied the following exclusion criteria:

- Studies that utilized injury models other than MPTP, 6-OHDA, rotenone or paraquat were excluded

- Studies that used invertebrate animal models were excluded

- Studies that did not systematically administer the agent were excluded

- Studies that did not aim to provide neuroprotection were excluded

In addition, we evaluated reference lists from the most recent articles in order to find additional studies that were not identified during the initial search. For agents that were recently reviewed, we provided an overview of the most important conclusions and augmented the conclusions of each study by reporting data from these more recent studies. The data from the resulting studies for all other agents were placed in a table accompanied by a summary text to provide a clear overview of all the preclinical data for each neuroprotective agent.

\section{INJURY MODELS}

In order to better comprehend the results of this systematic review, the main features of the included injury models are described below. Currently, several neurotoxins are available to induce experimental parkinsonism in animals. In this review, the four most frequently utilized methods are included, since they are generally considered as the best validated models. All four of these neurotoxins are capable of inducing the pathological hallmark of PD, neuronal cell loss in the substantia nigra (SN) [14]. The main contributing factor to this cell loss is mitochondrial dysfunction by inhibiting complex I, resulting in oxidative stress and eventually cell death (Fig. 1) [15].

\section{1-Methyl-4-Phenyl-1,2,3,6-Tetrahydropyridine (MPTP)}

MPTP is a commonly used neurotoxin for inducing PD in rodent and primate models since the discovery of its ability to cause parkinsonism in men [16]. MPTP is a lipophilic protoxin that rapidly crosses the blood-brain barrier (BBB) [17], where it selectively destroys dopamine (DA) neurons in the SN [18]. Extensive research has led to a relatively clear understanding of the mechanisms of action. Once MPTP crosses the $\mathrm{BBB}$, it is rapidly converted by a combination of mono-amino oxidase $\mathrm{B}$ (MAO-B) and other oxidation processes into the toxic MPP+ [19]. MPP+ is taken up via the dopamine transporter (DAT) into DA neurons where it triggers the formation of reactive oxygen species (ROS) [20]. Next, it accumulates inside the mitochondria and impairs the mitochondrial respiration by inhibition of complex I [21]. This leads to a combination of a reduction in cellular ATP and a further upregulation of ROS, which initiates cell death-related signalling pathways. Since rats do 


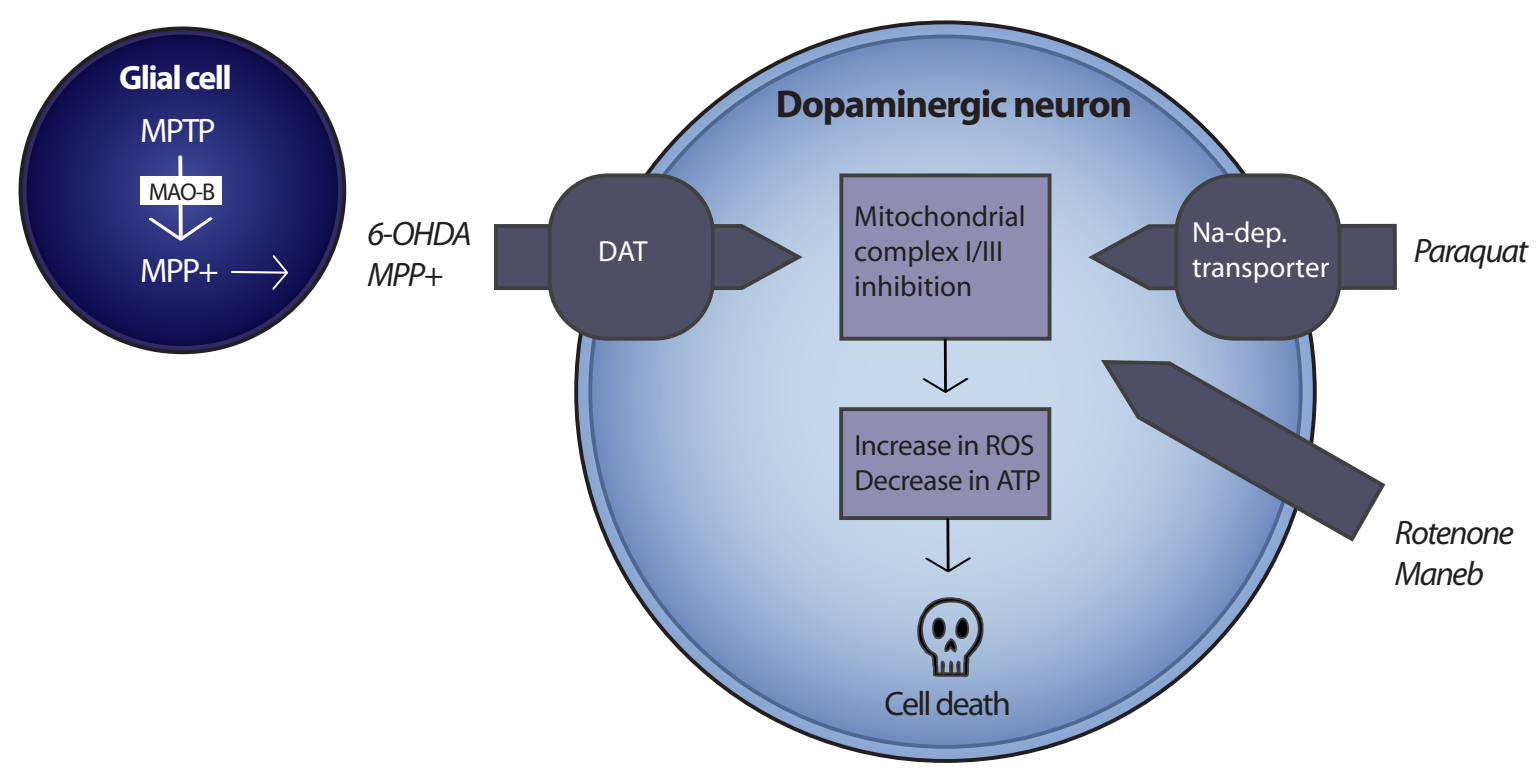

Fig. (1). Mechanisms of action of the neurotoxins MPTP, 6-OHDA, maneb and rotenone. MPTP is converted into MPP + after which it enters the dopaminergic neuron by the dopamine transporter (DAT). The same transporter is utilized by 6-OHDA to enter the cell. Paraquat enters the neuron by a natrium-dependent transporter (Na-dep transporter) and rotenone and maneb cross the cell membrane by diffusion. Once inside the cell, all neurotoxins inhibit the mitochrondial complex I or complex III, impairing the mitochondrial respiration. Eventually this leads to a decrease in ATP and an increase in reactive oxygen species (ROS), finally resulting in dopaminergic cell death.

not have sufficient MAO-B in the brain to convert MPTP, they are not suited for MPTP induced PD. However, some investigators directly inject MPP+ into rat brains. Because the mechanisms of MPTP intoxication are quite similar to features seen in PD, the MPTP model is seen as a valid PD model [14].

\section{6-Hydroxydopamine (6-OHDA)}

Together with MPTP, 6-OHDA is the most widely utilized neurotoxin to create $\mathrm{PD}$ models. In contrast to MPTP, 6-OHDA does not readily cross the BBB. Therefore, direct injection of 6-OHDA into the brain of test animals is necessary [14]. Currently, the mode of action is thought to be via increased oxidative stress and mitochondrial dysfunction, although the exact mechanism remains under discussion. It is clear, however, that administration of 6-OHDA leads to its conversion into ROS [22], a reduction of the antioxidant glutathione (GSH) and antioxidant enzyme superoxide dismutase (SOD) [23], elevated levels of iron in the SN [24] and inhibition of complex I and IV in the mitochondria [25], which leads to further oxidative stress. 6-OHDA lesions share common mechanisms of action with $\mathrm{PD}$ and is therefore regarded as an excellent model [14].

\section{Rotenone}

Rotenone was assessed in 2000 because of its MPTP-like inhibition of mitochondrial complex I [14]. However, since its introduction, rotenone has been under serious debate [26]. Like MPTP, rotenone readily crosses the $\mathrm{BBB}$, where it causes oxidative stress and accumulates inside the mitochondria dopaminergic neurons. However, the resulting reduction in ATP is not a cause of cell death. Rather, a large amount of ROS accounts for the damage in the $\mathrm{SN}$ region [27]. One important benefit of the rotenone model is that some investigators have reported the accumulation of $\alpha$ synuclein, one of the main characteristics of PD, while
MPTP and 6-OHDA are unable to induce this accumulation. In addition to rotenone's central effects, it also exerts systemic toxicity leading to cardiovascular events and gastrointestinal complications. This causes a high mortality rate of $30 \%$ in all treated animals. In addition, some rats seem to show an intrinsic resistance to rotenone (only $50 \%$ show neurodegeneration). Since experiments with rotenone require a large group of animals [28], this model is not preferred by most investigators, although it resembles specific PD hallmarks that are not induced by MPTP or 6OHDA [14].

\section{Paraquat and Maneb}

The herbicide paraquat and fungicide maneb have been associated with an increased incidence of PD [29]. Therefore, investigators have tried to create a model for PD with the use of these agents. Paraquat is transported through the BBB by a neutral amino transporter. Transport into the cell is regulated by $\mathrm{Na}+$-dependent reuptake [30], whereafter paraquat intoxicates the mitochondria by redox cycling and directly inhibits complex I [31]. Maneb, on the other hand, intoxicates the mitochondria by inhibiting complex III [14]. Progressive weight loss and respiratory problems account for a relatively high mortality rate [32]. Furthermore, the degree of neuronal cell death is minimal and variable [31]. For these reasons, the use of the paraquat/maneb model is limited [14]. However, paraquat and maneb induce toxicity gradually, which mimics the onset of PD better than the other neurotoxins [33].

\section{RESULTS}

Phase 1 of this review was conducted in December 2010 and identified 168 putative neuroprotective agents. After applying the CINAPS criteria and all exclusion criteria, 10 neuroprotective agents were included in a systemic literature review in phase II (i.e. melatonin, estrogen, nicotine, 

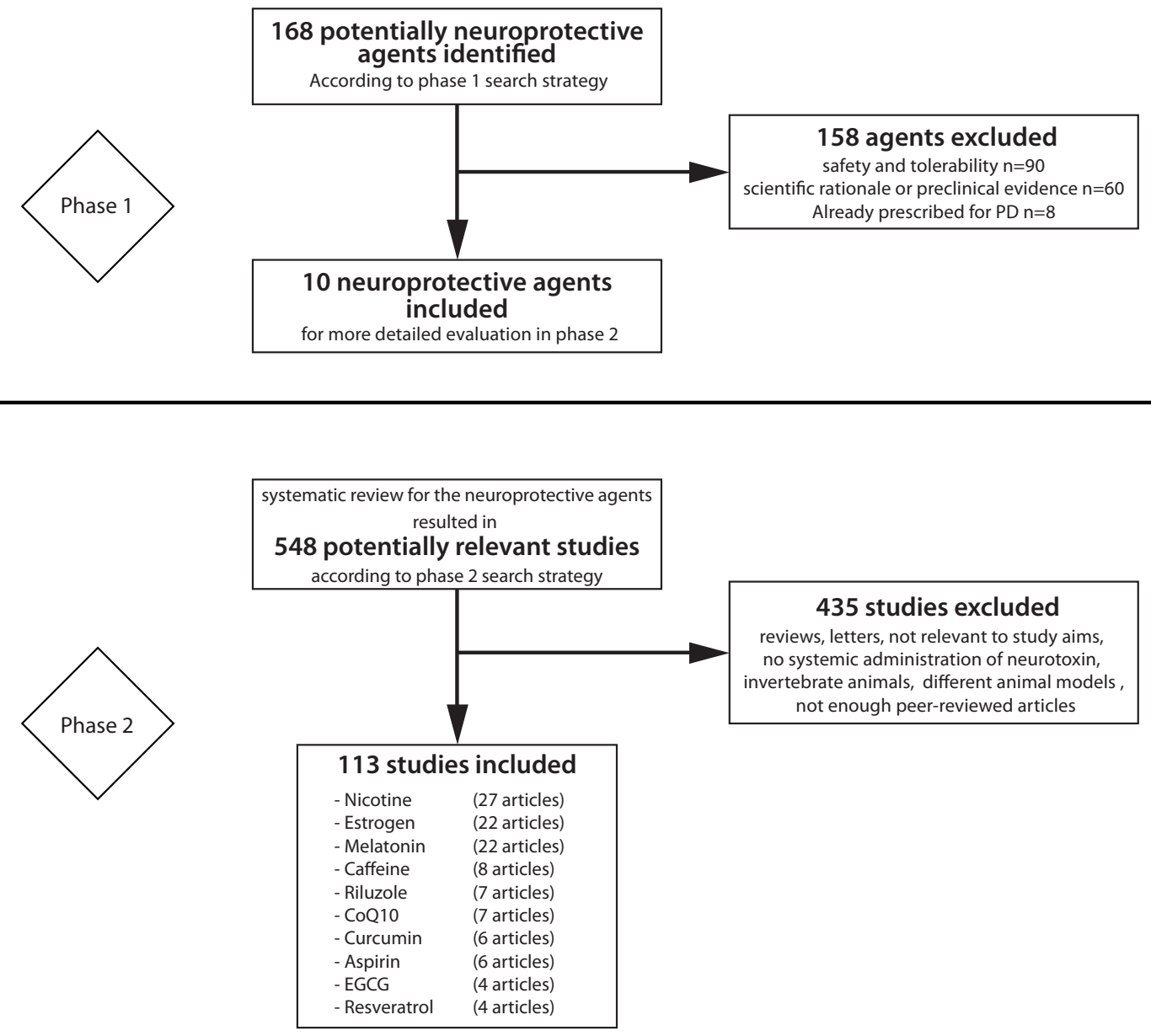

Fig. (2). Schematic overview of a systematic literature review of neuroprotective agents for Parkinson's disease. Phase 1-identification of potential neuroprotective agents. Phase 2-identification of relevant preclinical studies for each agent.

caffeine, riluzole, curcumin, coenzyme Q10, aspirin, EGCG and resveratrol). The systematic review, conducted in January 2011, resulted in 548 potentially relevant studies. Using the above mentioned exclusion criteria, we included 113 studies for in-depth evaluation. Fig. (2) schematically depicts the process. For each neuroprotective agent (with the exception of recently reviewed agents) a table with important features of the studies was composed (see Supplementary Material) with an accompanying summary text.

\section{Nicotine}

Various prospective studies have suggested a strong association between tobacco smoking and a decreased risk of PD [34]. Nicotine is one of the main constituents of tobacco and is known for its pharmacological effects, influencing the cholinergic nicotinic receptors in both the central and peripheral nervous system.

Substantial research has been conducted to investigate the putative neuroprotective properties of nicotine and the literature search revealed a total of 27 papers [35-61]. Quik et al., [62] reviewed the effects of nicotine on toxin-induced toxicity in rats, mice and non-human primates. The authors found that chronic intermittent administration of nicotine in non-human primates was partially neuroprotective. Furthermore, both intermittent and constant administration of nicotine in rats was shown to be neuroprotective, although it depended on the lesion size and location. In contrast with the results in monkeys and rats, data from studies in mice are controversial. Most studies that used intermittent dosage schemes found neuroprotective effects, whereas Quick et al., demonstrated that constant administration was not effective in mice. An important difference is that most mice were lesioned by MPTP, while 6-OHDA was utilized in rats. This suggests that nicotine might be more protective against 6OHDA-induced toxicity than MPTP. Other possible confounding differences are the plasma half-life of nicotine-5-10 $\mathrm{min}$ in mice, 1-2h in rats and monkeys - and the variation in distribution of nicotinic receptor subtypes. Several articles published before 2007 were left out in Quik et al.'s review, but the data from these earlier studies support their conclusions [37, 41, 46, 49, 51, 57]. Furthermore, the systematic search identified two papers published after 2007 that fitted the criteria of this systematic review [44, 60]. Takeuchi et al., [60] conducted an experiment with rotenoneinduced toxicity in mice. They showed that nicotine pretreatment significantly protected the striatum and substantia nigra from the deleterious effects induced by rotenone. Other investigators demonstrated that nicotine pretreatment was effective in rats and monkeys, but that posttreatment was not able to protect the animals [44].

It is noteworthy that a recent clinical trial among six male PD patients demonstrated that chronic high doses of nicotine 
improved motor scores, reduced dopaminergic treatment and had a potential beneficial effect on striatal dopamine transporter density $[63,64]$. Moreover, the authors reported that adverse effects were common but moderate and were pharmacologically manageable.

To conclude, the sum of epidemiological and preclinical data strongly suggests that nicotine has neuroprotective properties. The addition of encouraging results from a smallscale observational study elects nicotine as a strong candidate for large-scale neuroprotective clinical trials in the near future.

\section{7 $\beta$-Estradiol}

$17 \beta$-estradiol (E2) is a predominant female sex hormone with influences throughout the entire body. Since several epidemiological studies have shown a greater incidence of $\mathrm{PD}$ in men than women, extensive research is performed to investigate the possible neuroprotective effects of E2 [65, 66]. Since the compound is natural it is not patent protected. Several patents have been filed on its use for neuroprotection with Parkinson's disease and other neurodegenerative diseases since 2001 (WO02087552, and WO02069975).

Our systematic review resulted in 22 studies that fitted our criteria [67-88]. Bourque et al., [89] reviewed all 17 studies where MPTP models were utilized in 2009 [68, 70$73,75,76,79-88]$. They found that $\mathrm{E} 2$ is neuroprotective in MPTP mice models of both sexes when given pre- or postinjury with a physiological concentration $(102 \mathrm{pg} / \mathrm{ml})$. However, multiple higher doses of E2 or a single higher dose before MPTP injection did not show a neuroprotective effect. Two studies were not included in the review $[67,74]$ and three other studies conducted with the 6-OHDA-injury model $[69,78,90]$ further support the conclusions drawn in the review by Bourque et al., [89]. Murray et al., [69] reported that E2 treatment in female ovariectomized Sprague-Dawley rats decreased their lesions, but increased lesions in male gonadectomized Sprague-Dawley rats. Quesada and Micevych [77] partially supported these results by showing that ovariectomized female Long-Evans rats were protected against 6-OHDA lesioning by estrogen pretreatment. In contrast, Ferraz et al., [78] demonstrated no effect of E2 on 6-OHDA-induced tyrosine hydroxylase (TH)-cell loss in ovariectomized female Wistar rats. These inconsistent results for 6-OHDA studies could be due to differences in the locations of 6-OHDA injections, namely $\mathrm{SN}$ pars compacta $(\mathrm{SNpc})$ vs. medial forebrain. Although all three 6-OHDA studies administered doses above the physiological range, Ferraz et al., [78] used the highest dose, supporting the conclusion that doses in the physiological range are more effective. Also, the duration of Ferraz et al.'s [78] study was longer than the others, which could imply that E2 only protects for a limited time in the 6-OHDA model.

Four clinical trials with E2 have been performed among post-menopausal women with PD [91-94]. These studies reported positive results on symptomatic endpoints, but did not measure neuroprotection.

Overall, the majority of E2 studies showed promising neuroprotective properties in vivo. Furthermore, the association between a lower risk of PD and women appears to indicate that E2 is a promising compound. Unfortunately, no attention has been paid to the effects of E2 in paraquat and rotenone models; thus, future research should focus on these models.

\section{Melatonin (Supplementary Material Table A1)}

Melatonin is an indoleamine mainly synthesized from tryptophan in the human pineal gland and has been associated with circadian and seasonal rhythms. However, it is associated with many more processes, including neuroprotection.

Twenty-two papers have reported on the neuroprotective properties of melatonin in vivo [33, 95-115]. In 2005, Mayo et al., [116] conducted a literature review including 10 papers on this subject $[95,96,99-103,110-112]$. The authors summarized the results of in vivo studies conducted from 1995-2004. The studies were performed in both MPTP and 6-OHDA models and uniformly showed decreased neuron loss and increased DA levels with melatonin treatment. This led to the conclusion that melatonin was an agent with significant neuroprotective promises. However, the review did not include three studies with negative outcomes [105, 113, 114]. These investigators failed to show a neuroprotective effect of melatonin in MPTP-treated mice.

After Mayo et al.'s [116] review, nine other studies were performed. In 2006, Sharma et al., [107] demonstrated an increasing effect of a high dose of melatonin on the THimmunoreactivity in a 6-OHDA-rat model. A lower dose failed to show an effect in this study. In the same year, Saravanan et al., [106] conducted a study on the effects of melatonin on rotenone-injured rats. They showed that melatonin was protective against rotenone-induced cytotoxicity in neuron cells and in case of GSH depletion. The authors also measured higher activity of SOD and catalase in the brain when melatonin was administered. These results were supported by another rotenone study in which rats chronically exposed to rotenone were protected by co-treatment with melatonin [115]. In the same year, Capitelli et al., [98] conducted an MPTP test in rats. One dose of melatonin $(50 \mathrm{mg} / \mathrm{kg})$ protected the rats against the MPTP-induced TH neuron depletion after 24 hours, but no effect was measured after seven days. The same situation accounted for the results of the open field test. The investigators suggested that this could be due to low levels of circulating melatonin after seven days. Borah and Mohanakumar [97] hypothesized that parkinsonian neurotoxins that generate $\cdot \mathrm{OH}$ in a DA-enriched environment would be inducive to the production of 6OHDA and melatonin may act as a potent free radical scavenger, thereby protecting against 6-OHDA toxicity. The authors found support for this hypothesis in an experiment using levodopa and melatonin $(30 \mathrm{mg} / \mathrm{kg})$ on MPTP mice. Ma et al., [104] provided further evidence for the cellsparing effect of melatonin in the SNpc $(20 \mathrm{mg} / \mathrm{kg})$ with an experiment in MPTP mice. Tapias et al., [109] investigated the presence and role of nitric oxide synthase (NOS) isoforms in $\mathrm{SN}$ and the effect of melatonin $(20 \mathrm{mg} / \mathrm{kg})$ on NOS activity and mitochondrial dysfunction in another MPTP mice model. They found increased inducible NOS/inducible-mitochondrial NOS activity, nitrite levels, oxidative stress and complex I inhibition due to MPTP administration. In accordance to earlier studies, melatonin 
effectively counteracted these effects. Upon supporting evidence for the neuroprotective role of melatonin in the MPTP model, Tapias et al., [108] conducted a study using a rotenone model. Contradictory to the study of Saravanan et al., in 2006 [106], Tapias et al., [108] found a potentiating effect of melatonin $(10 \mathrm{mg} / \mathrm{kg})$ on rotenone toxicity, leading to additional striatal cell loss and DA depletion. Tapias et al., [108] explained the differences between the two studies as a result of differing endpoint measurements. They further stated that the contradiction between their rotenone study and most studies in MPTP and 6-OHDA studies was due to the downregulating effect of melatonin on DAT, which is a necessary transporter for MPTP and 6-OHDA toxicity, but not for rotenone. However, the results of Singhal et al., [33] did not support this explanation. Singhal et al., [33] used a paraquat/maneb injury in mice and found that melatonin (30 $\mathrm{mg} / \mathrm{kg}$ ) was effective in preventing DA depletion and $\mathrm{TH}-$ positive neuron degeneration. Because paraquat enters the cell via $\mathrm{Na}^{+}$-dependent uptake and not DAT, the neuroprotective effect was not due to the downregulation of DAT. This implies that melatonin, independent of DAT downregulation, has neuroprotective properties.

Three clinical trials using melatonin for PD patients were retrieved [117-119]. Shaw et al., [117] conducted a trial in four patients, but no notable effect was observed. Dowling et al., [118] and Medeiros et al., [119] conducted two clinical trials with melatonin to test the effect on sleep deprivation. They both concluded that there was a slight improvement, but Medeiros et al., did not find a significant improvement in motor function and Dowling et al., did not measure this feature. Both studies did not mention any serious side effects.

In summary, 18 of 22 studies in PD models demonstrated neuroprotective properties of melatonin, which makes it a substance with strong potential. Because of the positive outcomes in rodent models, primate experiments are recommended in order to provide further evidence.

\section{Caffeine (Supplementary Material Table A2)}

Caffeine is the most widely used psychoactive substance in the world due to its presence in coffee and other beverages [120]. Several epidemiological studies have linked coffee intake with a lower incidence of PD, suggesting neuroprotective properties for caffeine [121-123]. Multiple preclinical studies have been conducted to investigate this putative neuroprotective feature of caffeine.

The systematic review identified eight papers that reported on one of the four injury models and the effects of caffeine [124-131]. Chen et al., [125] found that caffeine (10 $\mathrm{mg} / \mathrm{kg}$ ) was neuroprotective when administered 10 minutes prior to four injections of MPTP. Caffeine attenuated the depletions in striatal DA, 3,4-Dihydroxyphenylacetic acid (DOPAC) and in DAT-binding sites. Xu et al., [131] were then motivated to investigate whether this effect would be subject to tolerance effects, as it is with the stimulatory effects of caffeine. They found that repeated daily intake of caffeine, which resulted in locomotor tolerance, did not attenuate the protective effects of caffeine on the MPTPinduced toxicity. The neuroprotective effects were then also established in a 6-OHDA model [126]. After several epidemiological studies suggested an interaction between estrogen and caffeine, $\mathrm{Xu}$ et al., [130] explored this association in a MPTP mouse model with both female and male mice. They found that, similar to previous results, caffeine attenuated the toxic effects of MPTP in male mice in a dose-dependent manner. In contrast, this result was not found in female mice and estrogen treatment also prevented this effect in young male mice. These data indicate a biological relationship between estrogen and caffeine for the risk of developing PD. In 2006, Aguiar et al., [124] showed that caffeine treatment after, instead of prior to, 6-OHDA injury was also protective. This finding was further supported by Singh et al., who investigated post- and preinjury treatment of caffeine in a MPTP model [128]. Xu et al., [129] then investigated the specific effective time frame for caffeine and reported that $30 \mathrm{mg} / \mathrm{kg}$ was effective $2 \mathrm{~h}$ prior to and $2 \mathrm{~h}$ after MPTP injection. In addition, the authors showed that the most important metabolites of caffeine, paraxanthine and theophylline, were also neuroprotective. To further refine the neuroprotective evidence for caffeine, Kachroo et al., [127] carried out a study in paraquat- and maneb-treated mice. Their results demonstrated that caffeine at $20 \mathrm{mg} / \mathrm{kg}$ significantly protected $\mathrm{TH}$-positive neurons in both pretreatment and posttreatment.

Altogether, these data imply that caffeine is a strong neuroprotectant in rodents for various injury models. Furthermore, precise pairing between toxins and caffeine treatment may not be necessary, since caffeine's effects are extended by its metabolites. Since caffeine has been extensively investigated in rodents, future research should concentrate on its effects in primates to establish firm evidence for future clinical trials.

\section{Riluzole (Supplementary Material Table A3)}

Riluzole is a selective $\mathrm{Na}^{+}$-channel blocker. It is registered for the treatment of amyotrophic lateral sclerosis (ALS) and is approved for use in the United States as Rilutek since 1996. The patent for this application was first filed by Rhone-Poulenc (now part of Sanofi Aventis) on 06-03-1992 (FR9202696).

Seven studies that fitted the criteria of this review were identified [132-138]. In 1994 three distinct studies were performed with riluzole in mice [133-135]. Jones-Humble et al., [133] investigated riluzole $(33 \mathrm{mg} / \mathrm{kg})$ in combination with MPTP. Unfortunately they found no significant difference in striatal DA levels compared to the MPTPinjured group. Boireau et al., [134, 135] conducted two studies in 1994, which investigated riluzole in rats with $\mathrm{MPP}+$ and mice with MPTP. In rats, a single dose $(8 \mathrm{mg} / \mathrm{kg})$ pre-injury significantly antagonized the MPP+-induced decrease in DA, but had no effect on extracellular DOPAC and homovanillic acid (HVA) levels [135]. In mice, Boireau et al., [134] showed that multiple doses of riluzole $(5 \mathrm{mg} / \mathrm{kg})$ were able to protect against MPTP-induced depletions in DA, DOPAC and HVA. The discrepancy in results from Boireau et al., and Jones-Humble et al., could be because the latter utilized a very high dose, which could have hindered the results. Another investigation demonstrated the effects of two subcutaneous injections of riluzole $(8 \mathrm{mg} / \mathrm{kg})$ in combination with a 6-OHDA injury in rats [137]. Riluzole attenuated the behavioural and biochemical deficits induced by 6-OHDA. The same researchers investigated whether 
reported riluzole neuroprotection in combination with MPTP was due to interference with MPP+ production by MAO-B inhibition [136]. They concluded that riluzole had no effect on MPP+ production; hence the observed protective effects were not caused by interference with MPTP metabolism. Araki et al., [132] further confirmed the protective effect of riluzole in MPTP-treated mice. They showed that this effect could be partially due to astrocyte activation. Following the studies in rodents, Obinu et al., [138] investigated riluzole in primates and showed that riluzole-treated marmosets preserved a better motor function and neurological performance when compared to those treated with MPTP.

To date, two clinical trials with riluzole have been performed with PD patients [139, 140]. A pilot study showed that riluzole was well tolerated at $100 \mathrm{mg}$ /day [139]. The second study investigated the effects on dyskinesia and the duration of the ON state [140]. Although riluzole extended the $\mathrm{ON}$ duration, this did not reach significance.

In short, riluzole has proven its neuroprotective effects in rodents and in a primate model. However, little is known about the effects on rotenone- and paraquat-induced toxicity. Once this gap of evidence is addressed, both the preclinical and the clinical results indicate the need for larger scale, longitudinal clinical trials.

\section{Coenzyme Q10 (Supplementary Material Table A4)}

Coenzyme Q10 (CoQ10) is a lipophilic, vitamin-like substance, also known as ubiquitone. It is well known for its function as a co-factor in the electron transport chain in complex I/II and its antioxidative effects.

Since 1995, seven preclinical studies have been conducted in order to investigate the neuroprotective effects of CoQ10 [141-147]. Schulz et al., [143] published a study on CoQ10 pretreatment $(400 \mathrm{mg} / \mathrm{kg})$ in MPTP mice, which did not show it to be protective and even worsened the symptoms in the experimental group. These results did not discourage a part of the research group, who performed another study [144]. In this investigation with MPTP mice, the investigators demonstrated a protective effect of a 200 $\mathrm{mg} / \mathrm{kg}$ CoQ10 pre- and posttreatment on DA levels and THimmunoreactive (IR) neuronfibers. Horvath et al., [142] continued the research on the neuroprotective properties of CoQ10 in a primate MPTP model. They reported a complete protective effect against dopaminergic cell loss by administrating $15-22 \mathrm{mg} / \mathrm{kg}$ of CoQ10. After five years a preclinical study was conducted by Abdin and Hamouda model [146] in a rotenone rat. CoQ10 $(200-600 \mathrm{mg} / \mathrm{kg})$ resulted in an increase in ATP levels and complex I activity, which had both been depleted as a result of rotenone treatment. In the same year, members of the research group from the first two studies, reported a dose-response study of CoQ10 (400-4800 mg/kg) in a chronic MPTP mice model [141]. However, CoQ10 was only effective in a dose of 1600 $\mathrm{mg} / \mathrm{kg}$ to counteract the MPTP-induced DA depletion, THneuron degeneration and $\alpha$-synuclein induction. SomayajuluNiţu et al., [147] demonstrated the effect of CoQ10 in paraquat-treated rats. A solution of $50 \mathrm{mg} / \mathrm{kg}$ of CoQ10 was reported to be effective in protecting against GSH depletion, TH-neuron degeneration and lipid peroxidation elevation. Yang et al., [145] assessed the combination of creatine and CoQ10 (1600-2000mg/kg) in MPTP mice and found a neuroprotective effect for both CoQ10 and creatine, as well as a synergetic effect when the two were combined. Notably, major differences were seen in the treatment dosages across studies. No author gave an explanation for the variation in effectiveness of the various doses.

Since 1997 there have been seven clinical trials to determine the symptomatic effect of CoQ10 [148-154]. The results of these studies are not conclusive. Shults et al., [149, 151] and Müller et al., [150] recommended further investigation of positive symptomatic outcomes, but Strijks et al., [148] and Storch et al., [152] failed to show an effect on symptomatic outcomes.

CoQ10 has been shown to be an effective neuroprotective agent in several injury models. However, this evidence is based on a wide array of therapeutic doses. It has been tested as a safe substance in both animals and humans, but remarkably, no studies have been conducted in the 6-OHDA-injury model and primates. In order to validate a new clinical trial in humans, studies in these injury models have to be performed and a standard neuroprotective dose has to be determined.

\section{Curcumin (Supplementary Material Table A5)}

Curcumin is an active polyphenolic compound of turmeric (Curcuma longa), which is extensively used as dietary spice in Indian food. In Western society, curcumin is used as a food additive because of its yellow colouring properties. Furthermore, curcumin is well known for its medicinal use in traditional Indian and Chinese medicine and several pharmacological properties have been established, including anti-inflammatory, antioxidant and anticarcogenic.

A total of six studies were identified in the systematic review [155-160]. Curcumin ( 3 × $50 \mathrm{~m} / \mathrm{kg})$ was investigated for the first time by Vajragupta et al., [158] using the MPTP injury model in mice. The posttreatment resulted in a significant attenuation of the MPTP-induced depletion in striatal DA and neuronal cell loss. Zbarsky et al., [160] utilized the same dose of curcumin to treat rats prior to 6OHDA injection. They showed that this pretreatment also protected the rats from neuronal cell loss and from depletion of DA and DOPAC. Rajeswari et al., [156] further elucidated the protective effects of curcumin. The authors demonstrated that pretreatment with $80 \mathrm{mg} / \mathrm{kg}$ of curcumin prevented MPTP-induced elevations in lipid peroxidation, SOD and catalase (CAT) activity and depletion of GSH levels in mice, which clearly shows the antioxidant properties of curcumin. The same research group reproduced their experiment with curcumin and one of its main metabolites, tetrahydrocurcumin [157]. Both compounds were shown to decrease depletion of striatal DA and DOPAC when administered prior to MPTP. Yu et al., [159] demonstrated that posttreatment of curcumin restored motor deficits and neuronal damage in MPTP-treated mice. Moreover, they showed that curcumin was also able to inhibit the c-Jun N-terminal kinase (JNK) pathway, suggesting that its neuroprotective effect is not only due to its antioxidant properties. Recently, another investigation by Khuwaja et al., [155] demonstrated the neuroprotective effects of pretreatment with curcumin in the 6-OHDA model in rats. Both motor deficits and neuronal damage were prevented by curcumin, which also had beneficial effects on 
the antioxidant status, with increasing GSH levels and activity of antioxidant enzymes. Notably, Rajeswari and Sabesan [157] found that curcumin inhibited MAO-B activity, which prevents the conversion of MPTP to its toxic metabolite MPP + . Therefore, the neuroprotective effects of curcumin in both studies by Rajeswari et al., are difficult to interpret. Since other studies utilized 6-OHDA or administered curcumin after MPTP injection, this does not apply to them. Although the MAO-B inhibiting activity of curcumin is problematic in the MPTP model, this action does have beneficial effects for PD patients since it inhibits the breakdown of DA.

To sum up, curcumin has proven neuroprotective effects in the 6-OHDA and MPTP models in rodents. Its antioxidant properties, in particular, seem to protect neurons from toxininduced damage. However, considerably more work will need to be done to provide definitive evidence of curcumin's disease-modifying capabilities, specifically studies in primates and using the rotenone and paraquat injury models. Moreover, since curcumin is frequently used in Indian food or as a colour additive, theoretically it is possible to conduct an epidemiological study to further determine the association between curcumin intake and the risk of developing PD.

\section{Aspirin (Supplementary Material Table A6)}

Inflammation is believed to be one of the important factors in the pathogenesis of PD. Moreover, it has been demonstrated that the enzyme cyclooxygenase (COX) and other inflammatory proteins are elevated in PD. Therefore, there has been significant interest in non-steroidal antiinflammatory drugs (NSAIDs), especially aspirin.

Six studies were identified that fitted the above mentioned criteria [161-166]. The first study that identified a putative neuroprotective feature of aspirin was conducted by Aubin et al., [161]. The authors reported that 60 and 100 $\mathrm{mg} / \mathrm{kg}$, but not $30 \mathrm{mg} / \mathrm{kg}$, of aspirin administered one hour prior to injury to mice, attenuated the MPTP-induced depletion in striatal DA in a dose-dependent way. In addition, they investigated the time course in which aspirin (100 mg/kg) administration was protective and showed that injection with aspirin from two hours before to two hours after injury significantly protected the mice. It is noteworthy that Aubin et al., found the selective COX1 inhibitor indomethacin to be ineffective. Teismann and Ferger [166] further tried to determine if COX1 or COX2 inhibition accounted for the neuroprotective effects of aspirin by treating mice with aspirin $(10,50$ or $100 \mathrm{mg} / \mathrm{kg})$ and the COX2 selective inhibitor meloxicam $(2,7.5$ or $50 \mathrm{mg} / \mathrm{kg}$ ) immediately before MPTP injection. They found that both drugs were able to protect mice from MPTP-induced toxicity. Consistent with Aubin et al.'s [161] data, only 50 and $100 \mathrm{mg} / \mathrm{kg}$ of aspirin were effective, whereas $10 \mathrm{mg} / \mathrm{kg}$ was ineffective. No difference in the effect of aspirin and meloxicam was found, suggesting that aspirin has an additional free radical scavenging property in addition to COX2 inhibition. Maharaj et al., [164] further established this effect. In their study, aspirin $(100 \mathrm{mg} / \mathrm{kg})$ and paracetamol $(100 \mathrm{mg} / \mathrm{kg})$ prevented $\mathrm{KCN}$-induced superoxide generation and lipid peroxidation. While paracetamol was a more effective antioxidant, aspirin completely blocked the debilitating effects of MPP+ on striatal DA in rats, whereas paracetamol was only able to partially block this effect. The same research group found that aspirin was able to significantly attenuate mitochondrial dysfunction in MPP+ infused rats, preventing the formation of ROS [165]. Also in 2006, the effects of aspirin pretreatment $(100 \mathrm{mg} / \mathrm{kg})$ on a combination of $\mathrm{MPP}+$ and 6OHDA injury in rats were investigated, utilizing microdialysis to determine the in vivo effects [162]. They demonstrated that aspirin was effective in both injury models, which was associated with ROS scavenging in the 6OHDA model, but not in the MPP+ model. Conversely, Gören et al., [163] did not find a neuroprotective effect of aspirin in the 6-OHDA model. Since they used a single nasogastric administration of aspirin $(100 \mathrm{~m} / \mathrm{kg})$ they speculated that they did not reach the effective dose required.

Interestingly, to date, no clinical trials among PD patients have been performed with aspirin, but several epidemiological studies have been published. A metaanalysis of six studies that investigated aspirin use and PD prevalence found no significant beneficial effect of aspirin [167]. The authors pointed out, however, that several sources of bias could cloud these results and thus further research is recommended.

To conclude, aspirin has been found to be neuroprotective in mice and rats with various injury models. These results are, however, not yet reproduced in primates and other injury models. Also, epidemiological studies have failed to establish a strong association between aspirin use and a lower prevalence of PD. Thus it is clear that aspirin has potential as a disease-modifying agent for $\mathrm{PD}$, but future studies, especially with rotenone and paraquat, are warranted to establish a greater degree of accuracy on this subject.

\section{Epigallocatechin Gallate (EGCG; Supplementary Material Table A7)}

EGCG, a catechin ubiquitously found in plants, is an important substance in green tea. It has been ascribed a wide range of therapeutic properties, including neuroprotection. Interestingly, there are several epidemiological studies that investigated an association between tea and PD [168, 169]. Among tea drinkers, the risk of developing PD was lower than in non-tea drinkers. This effect was thought to be especially influenced by EGCG.

The systematic review revealed four papers published from 2001 to 2010 that investigated the effects of EGCG in rodents [170-173]. Levites et al., [172] conducted a study to investigate the effect of green tea $(0.5-5 \mathrm{mg} / \mathrm{kg}$ EGCG) and EGCG $(2-10 \mathrm{mg} / \mathrm{kg})$ on neurodegeneration in MPTP-treated mice, which showed a protective effect against DA and TH depletion. In addition, green tea prevented MPTP-induced neuron loss and inhibited the upregulation of striatal SOD and catalase enzymes. Following this study, Choi et al., demonstrated similar results for neuron loss, DA and TH levels with $25 \mathrm{mg} / \mathrm{kg}$ EGCG administered by oral gavage and as green tea [170]. Also, they showed protection against the decreasing effects of MPTP administration on DOPAC and HVA levels. Seven years later, Leaver et al., noticed the need for an in vivo study for the 6-OHDA model in rats [171]. However, the administered EGCG (1-2mg/kg) did not show an effect on neuron loss or DA levels. Furthermore, they investigated the behavioural effects and reported mild 
improvements of EGCG-treated rats in curling bias and time to cross the beam tests compared to 6-OHDA lesioned rats, which were only significant at specific time points. Reznichenko et al., [173] reported the results of a combination therapy of rasagiline and EGCG. They showed an effect on DA levels in MPTP-treated mice with a dose of $10 \mathrm{mg} / \mathrm{kg}$ EGCG, but not with lower doses. Interestingly, the authors demonstrated neuroprotection with a combination of subeffective doses of EGCG and rasagiline.

In overview, the three MPTP studies showed promising results. Although Leaver et al., [171] failed to show positive outcomes, this could be explained by their use of a different injury model than other researchers and the relatively low dose. Further investigation is recommended in order to completely understand the neuroprotective effects of EGCG in rodents.

\section{Resveratrol (Supplementary Material Table A8)}

Resveratrol (RES), a polyphenol compound, is found in grapes and nuts and is an important component of red wine. Only recently, there has been an increasing interest in the anti-inflammatory, anti-oxidant and neuroprotective properties of RES. Patents have been filed on the use of resveratrol with Parkinson's disease and other neurodegenerative conditions since 1999 (WO2003103583 and WO9959561).

The systematic review resulted in four studies for which the neuroprotective effects of RES in PD were assessed [174-177]. In 2008, in a parallel effort, three independent research groups tried to determine the protective effects of resveratrol [174-176]. Both Lu et al., [175] and Blanchet et al., [174] investigated resveratrol treatment in combination with an MPTP injury in mice. Lu et al., [175] found that resveratrol administration $(20 \mathrm{mg} / \mathrm{kg})$ significantly attenuated the cytotoxicity evoked by MPTP, which included motor impairment and severe neuronal damage. Consistent with these results, Blanchet et al., [174] showed that resveratrol pretreatment (50 and $100 \mathrm{mg} / \mathrm{kg}$ ) prevented neuronal cell loss in the SN and striatal DA depletion. Also, resveratrol posttreatment $(10-40 \mathrm{~m} / \mathrm{kg})$ was found to be neuroprotective in the 6-OHDA-injury model in rats as reported by Jin et al., [176], although they found no apparent dose-dependent effect. They also showed that resveratrol decreased the mRNA and protein levels of TNF- $\alpha$ en COX2 , suggesting that an anti-inflammatory mechanism underlies the protective effects of resveratrol. The effects of resveratrol on the 6-OHDA injury in rats were further studied by Khan et al., [177]. Instead of posttreatment, they administered resveratrol $(20 \mathrm{mg} / \mathrm{kg})$ for two weeks prior to the induced injury. They discovered that resveratrol was not only capable of protecting neurons, but also of elevating the activity of antioxidant enzymes and decreasing the levels of thiobarbituric acid reactive substances (TBARS), protein carbonyl (PC) and phospholipase A2 (PA2), providing evidence for a possible antioxidant property of resveratrol as well.

Although these four studies showed encouraging results, there is a lack of evidence for the effects of resveratrol in animals other than rodents. Also, to date only MPTP and 6OHDA injury models have been investigated. Therefore, further experimental investigations are needed to determine if the positive results from these models can be replicated in other injury models and animals, before resveratrol can be tested in clinical PD trials. In addition, due to its abundance in red wine, it is appealing to investigate the difference between red wine drinkers and non-red wine drinkers in association with the risk of developing PD. To our knowledge, such an epidemiological study has not been performed.

\section{DISCUSSION AND FUTURE DIRECTIONS}

There is an urgent need for novel neuroprotective therapies for the fast growing number of patients diagnosed with PD. This review summarizes the in vivo preclinical data of neuroprotective compounds for the treatment of PD and provides a starting point for upcoming research. However, it must be noted, that this is not an extensive list of all currently known neuroprotective therapies. For example, therapies that require surgery or therapies in various stages of development are not considered. Moreover, due to the substantial differences in animals, utilized dose, injury model and severity, dose regime and endpoints it is quite difficult to draw firm conclusions as to which substance has the most potential for neuroprotection.

The results of this study show that some substances (e.g. nicotine or melatonin) have been investigated more extensively than others and have been effective in several injury models, whereas others have only recently been identified as neuroprotective (Table 1). It must be stressed that the frequency of published papers is not an indication of neuroprotective potency; it merely represents positioning in the development process. However, this study also revealed some obvious gaps, especially in time windows of efficacy and therapeutic dose, which should be addressed in future research. Moreover, it is clear that when compounds have been shown to be effective in all injury models there will be a greater chance that they will succeed in human trials. Since the various neurotoxins have distinct mechanisms of action, this could have implications for other processes in the pathophysiology of PD [178]. It is also possible that some neurotoxins can more precisely represent a distinct type of PD. However, as long as the underlying pathophysiology remains elusive, the predictive value of these models continues to be problematic as well [14]. Next to the limited value of current clinical trials to determine the neuroprotective effect of investigated agents, this constitutes an important obstacle in the translation of preclinical data to human trials. However, several efforts have been made to improve the quality of animal research. It is estimated that the current use of neurotoxins will eventually make way for transgenic animals or models in which animals more specifically represent the biochemical hallmarks of PD [14]. Another important translational drawback is the low bioavailability in humans of substances like resveratrol, EGCG, curcumin and coenzyme Q10 [179-182]. In order to address this issue, it is suggested for these substances to focus future investigations on pharmacokinetic studies. Optimizing the formulation would be of value for the bioavailability and stability of the compounds. Such efforts have for instance already been made with resveratrol, including studies that performed co-administration of metabolism inhibitors, the use of less instable analogues and the development of nanotechnology based delivery systems 
Table 1. Overview of the Developmental State of Ten Potential Neuroprotective Compounds

\begin{tabular}{|c|c|c|c|c|c|c|c|}
\hline Estrogen & $10+++/--$ & $+/-$ & & & & $\mathrm{x}$ & $\mathrm{x}$ \\
\hline Melatonin & ++++++++++/--- & ++ & + & $++/-$ & & & \\
\hline Riluzole & +++++ & + & & & + & & $\mathrm{x}$ \\
\hline Coenzyme Q10 & +++++ & & + & + & & & $\mathrm{x}$ \\
\hline Curcumin & ++++ & ++ & & & & & \\
\hline Aspirin & ++++ & ++ & & & & $\mathrm{x}$ & \\
\hline
\end{tabular}

Plusses (+) refer to the number of published papers with positive neuroprotective results, whereas minuses refer to negative results. Since this study has not systematically reviewed human trials, only crosses are used in this part, which indicate if such a trial has been conducted.

[183]. Similar studies could be performed with curcumin, EGCG and coenzyme Q10. Results from such studies should be used to find superior neuroprotective compounds in the Parkinson model. Due to the natural character of these compounds (except riluzole) patent protection for a neuroprotective application is not very strong, making funding of clinical research dependent on government funding.

The ten identified compounds in this review exhibit several modes of action, including anti-oxidative and antiinflammatory. Since PD has a multifactorial etiology, an interesting question is whether the combination of such distinct agents could result in synergistic effects [184], which could be investigated in future research. Another appealing detail is that most of these compounds represent a larger group of familiar compounds that could be neuroprotective as well. For instance, caffeine belongs to a larger group of A2A receptor antagonists, which as a group seems promising [185]. Modifying and fine-tuning such agents to maximize their efficacy and minimize side-effects could lead to superior patentable agents.

Overall, it is clear that there are still some urgent questions that need to be addressed to clear the way for effective neuroprotective treatments. For instance, there is still a high variance in administered doses and it is thus of high interest that the optimal dose of every putative neuroprotective agent is determined. Specialized, precise dose-finding studies could offer the solution to this predicament. Also, several compounds have not been tested in all available injury models and still lack enough preclinical evidence to progress into clinical development. Another important topic future research should focus on is the fundamental mode of action of specific compounds. Improving our knowledge about the underlying mechanisms could aid designing novel compounds with enhanced efficacy and/or safety. Along this line, we still lack a complete picture about the etiology of PD. All research into this issue remains of vital importance for the development of effective therapies.
In conclusion, this study depicts the preclinical data of ten promising neuroprotective agents in a clear and systematic manner. The results from this study facilitate the translation of preclinical data into human trials. While some of these compounds have already been tested in clinical use, none has been studied in an appropriately designed trial to determine a neuroprotective effect. Expecting qualitatively better neuroprotection trials, the data from this study provide a firm foundation for future research. This offers a better chance for the development of novel neuroprotective therapies and provides hope for patients suffering from PD.

\section{ACKNOWLEDGEMENTS}

The authors like to thank Chris Struiksma and Bert Poort for their cooperation and their useful feedback and ideas. We also like to thank the referees for their valuable input and Julia Chalinor for her English manuscript correction services.

\section{CONFLICT OF INTEREST}

Declared none.

\section{SUPPLEMENTARY MATERIAL}

Table A1-Table A8; Summarizing tables of all studies investigating the neuroprotective effects of melatonin, caffeine, riluzole, coenzyme Q10, curcumin, aspirin, EGCG and resveratrol respectively.

\section{REFERENCES}

[1] Gelb, D.J.; Oliver, E.; Gilman, S. Diagnostic criteria for Parkinson disease. Arch. Neurol., 1999, 56, 33-39.

[2] Yacoubian, T. A.; Standaert, D. G. Targets for neuroprotection in Parkinson's disease. Biochimica et Biophysica Acta, 2009, 1792, 676-687.

[3] Reichmann, H. Clinical criteria for the diagnosis of Parkinson's disease. Neurodegener Dis 2010, 7, 284-290.

[4] Fearnley, J.M.; Lees, A.J. Ageing and Parkinson's disease: substantia nigra regional selectivity. Brain, 1991, 114 (Pt 5), 22832301.

[5] Löhle, M.; Reichmann, H. Clinical neuroprotection in Parkinson's disease - still waiting for the breakthrough. J. Neurol. Sci, 2010, 289, 104-114. 
[6] Shoulson, I. Experimental neurotherapeutics: leaps and bounds. Arch. Neurol., 2002, 59, 689-691.

[7] Shoulson, I. Therapeutic directions for Parkinson's disease. Mov. Disord., 2010, 25 (Suppl 1), S152-154.

[8] Gabbay, J.; le May, A. Evidence based guidelines or collectively constructed "mindlines?" Ethnographic study of knowledge management in primary care. $B M J .$, 2004, 329, 1013.

[9] Pavese, N.; Kiferle, L.; Piccini, P. Neuroprotection and imaging studies in Parkinson's disease. Parkinsonism Relat. Disord., 2009, 15 (Suppl 4), S33-37.

[10] Hart, R. G.; Pearce, L.A.; Ravina, B.M.; Yaltho, T.C.; Marler, J.R. Neuroprotection trials in Parkinson's disease: systematic review. Mov. Disord., 2009, 24, 647-654.

[11] Kieburtz, K. Issues in neuroprotection clinical trials in Parkinson's disease. Neurology, 2006, 66, S50-57.

[12] Ravina, B.M.; Fagan, S.C.; Hart, R.G.; Hovinga, C.A.; Murphy, D.D.; Dawson, T.M.; Marler, J.R. Neuroprotective agents for clinical trials in Parkinson's disease: a systematic assessment. Neurology, 2003, 60, 1234-1240.

[13] Kwon, B.K.; Okon, E.; Hillyer, J.; Mann, C.; Baptiste, D.; Weaver, L.C.; Fehlings, M.G.; Tetzlaff, W.A Systematic Review of NonInvasive Pharmacologic Neuroprotective Treatments for Acute Spinal Cord Injury. J. Neurotrauma., 2011, 28, 1545-1588.

[14] Duty, S.; Jenner, P. Animal models of Parkinson's disease: a source of novel treatments and clues to the cause of the disease. $\mathrm{Br} . \mathrm{J}$. Pharmacol., 2011, 164, 1357-1391.

[15] Beal, M. F. Mitochondria, oxidative damage, and inflammation in Parkinson's disease. Ann. N. Y. Acad. Sci 2003, 991, 120-131.

[16] Davis, G.C.; Williams, A.C.; Markey, S.P.; Ebert, M.H.; Caine, E.D.; Reichert, C.M.; Kopin, I.J. Chronic Parkinsonism secondary to intravenous injection of meperidine analogues. Psychiatry Res., 1979, 1, 249-254.

[17] Riachi, N.J.; LaManna, J.C.; Harik, S.I. Entry of 1-methyl-4phenyl-1,2,3,6-tetrahydropyridine into the rat brain. J. Pharmacol. Exp. Ther., 1989, 249, 744-748.

[18] Burns, R.S.; Chiueh, C.C.; Markey, S.P.; Ebert, M.H.; Jacobowitz, D.M.; Kopin, I.J. A primate model of parkinsonism: selective destruction of dopaminergic neurons in the pars compacta of the substantia nigra by N-methyl-4-phenyl-1,2,3,6-tetrahydropyridine. Proc. Natl. Acad. Sci. USA., 1983, 80, 4546-4550.

[19] Chiba, K.; Trevor, A.; Castagnoli, N., Jr Metabolism of the neurotoxic tertiary amine, MPTP, by brain monoamine oxidase. Biochem. Biophys. Res. Commun., 1984, 120, 574-578.

[20] Tatton, N.A.; Kish, S.J. In situ detection of apoptotic nuclei in the substantia nigra compacta of 1-methyl-4-phenyl-1,2,3,6tetrahydropyridine-treated mice using terminal deoxynucleotidyl transferase labelling and acridine orange staining. Neuroscience, 1997, 77, 1037-1048.

[21] Nicklas, W.J.; Youngster, S.K.; Kindt, M.V.; Heikkila, R.E. MPTP, MPP+ and mitochondrial function. Life Sci., 1987, 40, 721-729.

[22] Mazzio, E.A.; Reams, R.R.; Soliman, K.F.A. The role of oxidative stress, impaired glycolysis and mitochondrial respiratory redox failure in the cytotoxic effects of 6-hydroxydopamine in vitro. Brain Res., 2004, 1004, 29-44.

[23] Perumal, A.S.; Gopal, V.B.; Tordzro, W.K.; Cooper, T.B.; Cadet, J.L. Vitamin E attenuates the toxic effects of 6-hydroxydopamine on free radical scavenging systems in rat brain. Brain Res. Bull., 1992, 29, 699-701.

[24] Oestreicher, E.; Sengstock, G.J.; Riederer, P.; Olanow, C.W.; Dunn, A J.; Arendash, G.W. Degeneration of nigrostriatal dopaminergic neurons increases iron within the substantia nigra: a histochemical and neurochemical study. Brain Res., 1994, 660, 818.

[25] Glinka, Y.; Gassen, M.; Youdim, M.B. Mechanism of 6hydroxydopamine neurotoxicity. J. Neural Transm. Suppl., 1997, 50, 55-66.

[26] Cicchetti, F.; Drouin-Ouellet, J.; Gross, R.E. Environmental toxins and Parkinson's disease: what have we learned from pesticideinduced animal models? Trends Pharmacol. Sci., 2009, 30, 475483.

[27] Sherer, T.B.; Betarbet, R.; Testa, C.M.; Seo, B.B.; Richardson, J.R.; Kim, J.H.; Miller, G.W.; Yagi, T.; Matsuno-Yagi, A.; Greenamyre, J. T. Mechanism of toxicity in rotenone models of Parkinson's disease. J. Neurosci., 2003, 23, 10756-10764.

[28] Betarbet, R.; Sherer, T.B.; MacKenzie, G.; Garcia-Osuna, M.; Panov, A.V.; Greenamyre, J.T. Chronic systemic pesticide exposure reproduces features of Parkinson's disease. Nat. Neurosci., 2000, 3, 1301-1306.

[29] Costello, S.; Cockburn, M.; Bronstein, J.; Zhang, X.; Ritz, B. Parkinson's disease and residential exposure to maneb and paraquat from agricultural applications in the central valley of California. Am. J. Epidemiol., 2009, 169, 919-926.

[30] Shimizu, K.; Ohtaki, K.; Matsubara, K.; Aoyama, K.; Uezono, T.; Saito, O.; Suno, M.; Ogawa, K.; Hayase, N.; Kimura, K.; Shiono, H. Carrier-mediated processes in blood--brain barrier penetration and neural uptake of paraquat. Brain Res., 2001, 906, 135-142.

[31] Miller, G.W. Paraquat: the red herring of Parkinson's disease research. Toxicol. Sci 2007, 100, 1-2.

[32] Saint-Pierre, M.; Tremblay, M.-E.; Sik, A.; Gross, R.E.; Cicchetti, F. Temporal effects of paraquat/maneb on microglial activation and dopamine neuronal loss in older rats. J. Neurochem., 2006, 98, 760772.

[33] Singhal, N.K.; Srivastava, G.; Patel, D.K.; Jain, S.K.; Singh, M.P. Melatonin or silymarin reduces maneb- and paraquat-induced Parkinson's disease phenotype in the mouse. J. Pineal Res., 2010, 50, 97-109.

[34] Allam, M.F.; Campbell, M.J.; Hofman, A.; Del Castillo, A.S.; Fernández-Crehuet Navajas, R. Smoking and Parkinson's disease: systematic review of prospective studies. Mov. Disord., 2004, 19, 614-621.

[35] Abin-Carriquiry, J.A.; McGregor-Armas, R.; Costa, G.; Urbanavicius, J.; Dajas, F. Presynaptic involvement in the nicotine prevention of the dopamine loss provoked by 6-OHDA administration in the substantia nigra. Neurotox. Res., 2002, 4, 133139.

[36] Behmand, R.A.; Harik, S.I. Nicotine enhances 1-methyl-4-phenyl1,2,3,6-tetrahydropyridine neurotoxicity. J. Neurochem., 1992, 58, 776-779.

[37] Carr, L.A.; Basham, J.K. Effects of tobacco smoke constituents on MPTP-induced toxicity and monoamine oxidase activity in the mouse brain. Life Sci., 1991, 48, 1173-1177.

[38] Carr, L.A.; Rowell, P.P. Attenuation of 1-methyl-4-phenyl-1,2,3,6tetrahydropyridine-induced neurotoxicity by tobacco smoke. Neuropharmacology, 1990, 29, 311-314.

[39] Costa, G.; Abin-Carriquiry, J.A.; Dajas, F. Nicotine prevents striatal dopamine loss produced by 6-hydroxydopamine lesion in the substantia nigra. Brain Res., 2001, 888, 336-342.

[40] Ferger, B.; Spratt, C.; Earl, C.D.; Teismann, P.; Oertel, W.H.; Kuschinsky, K. Effects of nicotine on hydroxyl free radical formation in vitro and on MPTP-induced neurotoxicity in vivo. Naunyn Schmiedebergs Arch. Pharmacol., 1998, 358, 351-359.

[41] Fung, Y.K.; Fiske, L.A.; Lau, Y.-S. Chronic administration of nicotine fails to alter the MPTP-induced neurotoxicity in mice. Gen. Pharmacol. Vasc. Syst., 1991, 22, 669-672.

[42] Gao, Z.G.; Cui, W.Y.; Zhang, H.T.; Liu, C.G. Effects of nicotine on 1-methyl-4-phenyl-1,2,5,6-tetrahydropyridine-induced depression of striatal dopamine content and spontaneous locomotor activity in C57 black mice. Pharmacol. Res., 1998, 38, 101-106.

[43] Hadjiconstantinou, M.; Hubble, J.P.; Wemlinger, T.A.; Neff, N.H. Enhanced MPTP neurotoxicity after treatment with isoflurophate or cholinergic agonists. J. Pharmacol. Exp. Ther., 1994, 270, 639644.

[44] Huang, L.Z.; Parameswaran, N.; Bordia, T.; Michael McIntosh, J.; Quik, M. Nicotine is neuroprotective when administered before but not after nigrostriatal damage in rats and monkeys. J. Neurochem., 2009, 109, 826-837.

[45] Janson, A.M.; Fuxe, K.; Agnati, L.F.; Kitayama, I.; Härfstrand, A.; Andersson, K.; Goldstein, M. Chronic nicotine treatment counteracts the disappearance of tyrosine-hydroxylaseimmunoreactive nerve cell bodies, dendrites and terminals in the mesostriatal dopamine system of the male rat after partial hemitransection. Brain Res., 1988, 455, 332-345.

[46] Janson, A.M.; Fuxe, K.; Sundström, E.; Agnati, L.F.; Goldstein, M. Chronic nicotine treatment partly protects against the 1-methyl-4phenyl-2,3,6-tetrahydropyridine-induced degeneration of nigrostriatal dopamine neurons in the black mouse. Acta Physiol. Scand., 1988, 132, 589-591.

[47] Janson, A.M.; Fuxe, K.; Goldstein, M. Differential effects of acute and chronic nicotine treatment on MPTP-(1-methyl-4-phenyl1,2,3,6-tetrahydropyridine) induced degeneration of nigrostriatal dopamine neurons in the black mouse. Clin. Investig., 1992, 70, 232-238. 
[48] Khwaja, M.; McCormack, A.; McIntosh, J.M.; Di Monte, D.A.; Quik, M. Nicotine partially protects against paraquat-induced nigrostriatal damage in mice; link to alpha6beta2* nAChRs. $J$. Neurochem., 2007, 100, 180-190.

[49] Maggio, R.; Riva, M.; Vaglini, F.; Fornai, F.; Molteni, R.; Armogida, M.; Racagni, G.; Corsini, G.U. Nicotine prevents experimental parkinsonism in rodents and induces striatal increase of neurotrophic factors. J. Neurochem., 1998, 71, 2439-2446.

[50] Parain, K.; Hapdey, C.; Rousselet, E.; Marchand, V.; Dumery, B.; Hirsch, E. C. Cigarette smoke and nicotine protect dopaminergic neurons against the 1-methyl-4-phenyl-1,2,3,6-tetrahydropyridine Parkinsonian toxin. Brain Res., 2003, 984, 224-232.

[51] Parain, K.; Marchand, V.; Dumery, B.; Hirsch, E. Nicotine, but not cotinine, partially protects dopaminergic neurons against MPTPinduced degeneration in mice. Brain Res., 2001, 890, 347-350.

[52] Perry, T.L.; Hansen, S.; Jones, K. Exposure to cigarette smoke does not decrease the neurotoxicity of N-methyl-4-phenyl-1,2,3,6tetrahydropyridine in mice. Neurosci. Lett., 1987, 74, 217-220.

[53] Quik, M.; Parameswaran, N.; McCallum, S.E.; Bordia, T.; Bao, S.; McCormack, A.; Kim, A.; Tyndale, R. F.; Langston, J. W.; Di Monte, D. A. Chronic oral nicotine treatment protects against striatal degeneration in MPTP-treated primates. J. Neurochem., 2006, 98, 1866-1875.

[54] Quik, M.; Chen, L.; Parameswaran, N.; Xie, X.; Langston, J.W.; McCallum, S.E. Chronic oral nicotine normalizes dopaminergic function and synaptic plasticity in 1-methyl-4-phenyl-1,2,3,6tetrahydropyridine-lesioned primates. J. Neurosci., 2006, 26, 46814689.

[55] Ryan, R.E.; Ross, S.A.; Drago, J.; Loiacono, R.E. Dose-related neuroprotective effects of chronic nicotine in 6-hydroxydopamine treated rats, and loss of neuroprotection in alpha4 nicotinic receptor subunit knockout mice. Br. J. Pharmacol., 2001, 132, 1650-1656.

[56] Sershen, H.; Hashim, A.; Wiener, H.L.; Lajtha, A. Effect of chronic oral nicotine on dopaminergic function in the MPTP-treated mouse. Neurosci. Lett., 1988, 93, 270-274.

[57] Sershen, H.; Mason, M.F.; Reith, M.E.A.; Hashim, A.; Lajtha, A. Effect of nicotine and amphetamine on the neurotoxicity of $\mathrm{N}$ methyl-4-phenyl-1,2,3,6-tetrahydropyridine (MPTP) in mice. Neuropharmacology, 1986, 25, 1231-1234.

[58] Shahi, G.S.; Das, N.P.; Moochhala, S.M. 1-Methyl-4-phenyl1,2,3,6-tetrahydropyridine-induced neurotoxicity: partial protection against striato-nigral dopamine depletion in $\mathrm{C} 57 \mathrm{BL} / 6 \mathrm{~J}$ mice by cigarette smoke exposure and by beta-naphthoflavonepretreatment. Neurosci. Lett., 1991, 127, 247-250.

[59] Soto-Otero, R.; Méndez-Alvarez, E.; Hermida-Ameijeiras, A.; López-Real, A.M.; Labandeira-García, J.L. Effects of (-)-nicotine and (-)-cotinine on 6-hydroxydopamine-induced oxidative stress and neurotoxicity: relevance for Parkinson's disease. Biochem. Pharmacol., 2002, 64, 125-135.

[60] Takeuchi, H.; Yanagida, T.; Inden, M.; Takata, K.; Kitamura, Y.; Yamakawa, K.; Sawada, H.; Izumi, Y.; Yamamoto, N.; Kihara, T.; Uemura, K.; Inoue, H.; Taniguchi, T.; Akaike, A.; Takahashi, R.; Shimohama, S. Nicotinic receptor stimulation protects nigral dopaminergic neurons in rotenone-induced Parkinson's disease models. J. Neurosci. Res., 2009, 87, 576-585.

[61] Visanji, N.P.; O'Neill, M.J.; Duty, S. Nicotine, but neither the alpha4beta2 ligand RJR2403 nor an alpha7 nAChR subtype selective agonist, protects against a partial 6-hydroxydopamine lesion of the rat median forebrain bundle. Neuropharmacology, 2006, 51, 506-516.

[62] Quik, M.; O’Neill, M.; Perez, X.A. Nicotine neuroprotection against nigrostriatal damage: importance of the animal model. Trends Pharmacol. Sci.,, 2007, 28, 229-235.

[63] Itti, E.; Villafane, G.; Malek, Z.; Brugières, P.; Capacchione, D.; Itti, L.; Maison, P.; Cesaro, P.; Meignan, M. Dopamine transporter imaging under high-dose transdermal nicotine therapy in Parkinson's disease: an observational study. Nucl. Med. Commun., 2009, 30, 513-518.

[64] Villafane, G.; Cesaro, P.; Rialland, A.; Baloul, S.; Azimi, S.; Bourdet, C.; Le Houezec, J.; Macquin-Mavier, I.; Maison, P. Chronic high dose transdermal nicotine in Parkinson's disease: an open trial. Eur. J. Neurol., 2007, 14, 1313-1316.

[65] Taylor, K.S.M.; Cook, J.A.; Counsell, C.E. Heterogeneity in male to female risk for Parkinson's disease. J. Neurol. Neurosurg. Psychiatr., 2007, 78, 905-906.
[66] Wooten, G.F.; Currie, L.J.; Bovbjerg, V.E.; Lee, J.K.; Patrie, J. Are men at greater risk for Parkinson's disease than women? J. Neurol. Neurosurg. Psychiatr., 2004, 75, 637-639.

[67] Tripanichkul, W.; Sripanichkulchai, K.; Duce, J. A.; Finkelstein, D.I. 17Beta-estradiol reduces nitrotyrosine immunoreactivity and increases SOD1 and SOD2 immunoreactivity in nigral neurons in male mice following MPTP insult. Brain Res., 2007, 1164, 24-31.

[68] D’Astous, M.; Morissette, M.; Tanguay, B.; Callier, S.; Di Paolo, T. Dehydroepiandrosterone (DHEA) such as 17beta-estradiol prevents MPTP-induced dopamine depletion in mice. Synapse, 2003, 47, 10-14.

[69] Murray, H.E.; Pillai, A.V.; McArthur, S.R.; Razvi, N.; Datla, K.P.; Dexter, D.T.; Gillies, G.E. Dose- and sex-dependent effects of the neurotoxin 6-hydroxydopamine on the nigrostriatal dopaminergic pathway of adult rats: differential actions of estrogen in males and females. Neuroscience, 2003, 116, 213-222.

[70] D'Astous, M.; Morissette, M.; Di Paolo, T. Effect of estrogen receptor agonists treatment in MPTP mice: evidence of neuroprotection by an ER alpha agonist. Neuropharmacology, 2004, 47, 1180-1188.

[71] Ookubo, M.; Yokoyama, H.; Takagi, S.; Kato, H.; Araki, T. Effects of estrogens on striatal damage after 1-methyl-4-phenyl-1,2,3,6tetrahydropyridine (MPTP) neurotoxicity in male and female mice. Mol. Cell. Endocrinol., 2008, 296, 87-93.

[72] Dluzen, D.E.; McDermott, J.L.; Liu, B. Estrogen alters MPTPinduced neurotoxicity in female mice: effects on striatal dopamine concentrations and release. J. Neurochem., 1996, 66, 658-666.

[73] Morissette, M.; Al Sweidi, S.; Callier, S.; Di Paolo, T. Estrogen and SERM neuroprotection in animal models of Parkinson's disease. Mol. Cell. Endocrinol., 2008, 290, 60-69.

[74] Dluzen, D.E.; McDermott, J.L.; Liu, B. Estrogen as a neuroprotectant against MPTP-induced neurotoxicity in C57/B1 mice. Neurotoxicol. Teratol., 1996, 18, 603-606.

[75] Shughrue, P.J. Estrogen attenuates the MPTP-induced loss of dopamine neurons from the mouse SNc despite a lack of estrogen receptors (ERalpha and ERbeta). Exp. Neurol., 2004, 190, 468-477.

[76] Tripanichkul, W.; Sripanichkulchai, K.; Finkelstein, D.I. Estrogen down-regulates glial activation in male mice following 1-methyl-4phenyl-1,2,3,6-tetrahydropyridine intoxication. Brain Res., 2006, 1084, 28-37.

[77] Quesada, A.; Micevych, P.E. Estrogen interacts with the IGF-1 system to protect nigrostriatal dopamine and maintain motoric behavior after 6-hydroxdopamine lesions. J. Neurosci. Res., 2004, 75, 107-116.

[78] Ferraz, A.C.; Xavier, L.L.; Hernandes, S.; Sulzbach, M.; Viola, G.G.; Anselmo-Franci, J.A.; Achaval, M.; Da Cunha, C. Failure of estrogen to protect the substantia nigra pars compacta of female rats from lesion induced by 6-hydroxydopamine. Brain Res., 2003, 986, 200-205.

[79] D’Astous, M.; Mendez, P.; Morissette, M.; Garcia-Segura, L.M.; Di Paolo, T. Implication of the phosphatidylinositol-3 kinase/protein kinase B signaling pathway in the neuroprotective effect of estradiol in the striatum of 1-methyl-4-phenyl-1,2,3,6tetrahydropyridine mice. Mol. Pharmacol., 2006, 69, 1492-1498.

[80] Ekue, A.; Boulanger, J.-F.; Morissette, M.; Di Paolo, T. Lack of effect of testosterone and dihydrotestosterone compared to $17 \mathrm{beta}$ oestradiol in 1-methyl-4-phenyl-1,2,3,6, tetrahydropyridine-mice. J. Neuroendocrinol., 2002, 14, 731-736.

[81] Callier, S.; Morissette, M.; Grandbois, M.; Pélaprat, D.; Di Paolo, T. Neuroprotective properties of 17beta-estradiol, progesterone, and raloxifene in MPTP C57B1/6 mice. Synapse, 2001, 41, 131138.

[82] Jourdain, S.; Morissette, M.; Morin, N.; Di Paolo, T. Oestrogens prevent loss of dopamine transporter (DAT) and vesicular monoamine transporter (VMAT2) in substantia nigra of 1-methyl4-phenyl-1,2,3,6-tetrahydropyridine mice. J. Neuroendocrinol., 2005, 17, 509-517.

[83] Grandbois, M.; Morissette, M.; Callier, S.; Di Paolo, T. Ovarian steroids and raloxifene prevent MPTP-induced dopamine depletion in mice. Neuroreport, 2000, 11, 343-346.

[84] D’Astous, M.; Morissette, M.; Callier, S.; Di Paolo, T. Regulation of striatal preproenkephalin mRNA levels in MPTP-lesioned mice treated with estradiol. J. Neurosci. Res., 2005, 80, 138-144.

[85] Ramirez, A. D.; Liu, X.; Menniti, F. S. Repeated estradiol treatment prevents MPTP-induced dopamine depletion in male mice. Neuroendocrinology, 2003, 77, 223-231. 
[86] Callier, S.; Morissette, M.; Grandbois, M.; Di Paolo, T. Stereospecific prevention by 17 beta-estradiol of MPTP-induced dopamine depletion in mice. Synapse, 2000, 37, 245-251.

[87] Dluzen, D.E.; McDermott, J.L.; Anderson, L.I. Tamoxifen eliminates estrogen's neuroprotective effect upon MPTP-induced neurotoxicity of the nigrostriatal dopaminergic system. Neurotox. Res., 2001, 3, 291-300.

[88] Miller, D.B.; Ali, S.F.; O'Callaghan, J.P.; Laws, S.C. The impact of gender and estrogen on striatal dopaminergic neurotoxicity. Ann. N. Y. Acad. Sci., 1998, 844, 153-165.

[89] Bourque, M.; Dluzen, D.E.; Di Paolo, T. Neuroprotective actions of sex steroids in Parkinson's disease. Front Neuroendocrinol., 2009, 30, 142-157.

[90] Quesada, A.; Lee, B.Y.; Micevych, P.E. PI3 kinase/Akt activation mediates estrogen and IGF-1 nigral DA neuronal neuroprotection against a unilateral rat model of Parkinson's disease. Dev. Neurobiol., 2008, 68, 632-644.

[91] Nicoletti, A.; Arabia, G.; Pugliese, P.; Nicoletti, G.; Torchia, G.; Condino, F.; Morgante, L.; Quattrone, A.; Zappia, M. Hormonal replacement therapy in women with Parkinson disease and levodopa-induced dyskinesia: a crossover trial. Clin. Neuropharmacol., 2007, 30, 276-280.

[92] Strijks, E.; Kremer, J.A.; Horstink, M.W. Effects of female sex steroids on Parkinson's disease in postmenopausal women. Clin. Neuropharmacol., 1999, 22, 93-97.

[93] Tsang, K.L.; Ho, S.L.; Lo, S.K. Estrogen improves motor disability in parkinsonian postmenopausal women with motor fluctuations. Neurology, 2000, 54, 2292-2298.

[94] Blanchet, P.J.; Fang, J.; Hyland, K.; Arnold, L.A.; Mouradian, M.M.; Chase, T.N. Short-term effects of high-dose 17 beta-estradiol in postmenopausal PD patients: a crossover study. Neurology, 1999, 53, 91-95.

[95] Acuña-Castroviejo, D.; Coto-Montes, A.; Gaia Monti, M.; Ortiz, G.G.; Reiter, R.J. Melatonin is protective against MPTP-induced striatal and hippocampal lesions. Life Sci., 1997, 60, PL23-29.

[96] Antolín, I.; Mayo, J.C.; Sainz, R.M.; del Brío, M. de los A.; Herrera, F.; Martín, V.; Rodríguez, C. Protective effect of melatonin in a chronic experimental model of Parkinson's disease. Brain Res., 2002, 943, 163-173.

[97] Borah, A.; Mohanakumar, K.P. Melatonin inhibits 6hydroxydopamine production in the brain to protect against experimental parkinsonism in rodents. J. Pineal Res., 2009, 47, 293-300.

[98] Capitelli, C.; Sereniki, A.; Lima, M.M.S.; Reksidler, A.B.; Tufik, S.; Vital, M.A.B.F. Melatonin attenuates tyrosine hydroxylase loss and hypolocomotion in MPTP-lesioned rats. Eur. J. Pharmacol., 2008, 594, 101-108.

[99] Chen, S.T.; Chuang, J.I.; Hong, M.H.; Li, E.I.-C. Melatonin attenuates MPP+-induced neurodegeneration and glutathione impairment in the nigrostriatal dopaminergic pathway. J. Pineal Res., 2002, 32, 262-269.

[100] Dabbeni-Sala, F.; Di Santo S; Franceschini, D.; Skaper, S.D.; Giusti, P. Melatonin protects against 6-OHDA-induced neurotoxicity in rats: a role for mitochondrial complex I activity. FASEB. J. 2001, 15, 164-170.

[101] Jin, B.K.; Shin, D.Y.; Jeong, M.Y.; Gwag, M.R.; Baik, H.W.; Yoon, K.S.; Cho, Y.H.; Joo, W.S.; Kim, Y.S.; Baik, H.H. Melatonin protects nigral dopaminergic neurons from 1-methyl-4phenylpyridinium (MPP+) neurotoxicity in rats. Neurosci. Lett., 1998, 245, 61-64.

[102] Khaldy, H.; Escames, G.; León, J.; Bikjdaouene, L.; AcuñaCastroviejo, D. Synergistic effects of melatonin and deprenyl against MPTP-induced mitochondrial damage and DA depletion. Neurobiol. Aging, 2003, 24, 491-500.

[103] Kim, Y.S.; Joo, W.S.; Jin, B.K.; Cho, Y.H.; Baik, H.H.; Park, C.W. Melatonin protects 6-OHDA-induced neuronal death of nigrostriatal dopaminergic system. Neuroreport, 1998, 9, 23872390.

[104] Ma, J.; Shaw, V.E.; Mitrofanis, J. Does melatonin help save dopaminergic cells in MPTP-treated mice? Parkinsonism Relat. Disord., 2009, 15, 307-314.

[105] Morgan, W.W.; Nelson, J.F. Chronic administration of pharmacological levels of melatonin does not ameliorate the MPTP-induced degeneration of the nigrostriatal pathway. Brain Res., 2001, 921, 115-121.
[106] Saravanan, K.S.; Sindhu, K.M.; Mohanakumar, K.P. Melatonin protects against rotenone-induced oxidative stress in a hemiparkinsonian rat model. J. Pineal Res., 2007, 42, 247-253.

[107] Sharma, R.; McMillan, C.R.; Tenn, C.C.; Niles, L.P. Physiological neuroprotection by melatonin in a 6-hydroxydopamine model of Parkinson's disease. Brain Res., 2006, 1068, 230-236.

[108] Tapias, V.; Cannon, J.R.; Greenamyre, J.T. Melatonin treatment potentiates neurodegeneration in a rat rotenone Parkinson's disease model. J. Neurosci. Res., 2010, 88, 420-427.

[109] Tapias, V.; Escames, G.; López, L.C.; López, A.; Camacho, E.; Carrión, M.D.; Entrena, A.; Gallo, M.A.; Espinosa, A.; AcuñaCastroviejo, D. Melatonin and its brain metabolite N(1)-acetyl-5methoxykynuramine prevent mitochondrial nitric oxide synthase induction in parkinsonian mice. J. Neurosci. Res., 2009, 87, 30023010

[110] Thomas, B.; Mohanakumar, K.P. Melatonin protects against oxidative stress caused by 1-methyl-4-phenyl-1,2,3,6tetrahydropyridine in the mouse nigrostriatum. J. Pineal Res. 2004, 36, 25-32.

[111] Joo, W.S.; Jin, B.K.; Park, C.W.; Maeng, S.H.; Kim, Y.S Melatonin increases striatal dopaminergic function in 6-OHDAlesioned rats. Neuroreport., 1998, 9, 4123-4126.

[112] Ortiz, G.G.; Crespo-López, M.E.; Morán-Moguel, C.; García, J.J.; Reiter, R.J.; Acuña-Castroviejo, D. Protective role of melatonin against MPTP-induced mouse brain cell DNA fragmentation and apoptosis in vivo. Neuro Endocrinol. Lett., 2001, 22, 101-108.

[113] Itzhak, Y.; Martin, J.L.; Black, M.D.; Ali, S.F. Effect of melatonin on methamphetamine- and 1-methyl-4-phenyl-1,2,3,6tetrahydropyridine-induced dopaminergic neurotoxicity and methamphetamine-induced behavioral sensitization. Neuropharmacology, 1998, 37, 781-791.

[114] van der Schyf, C.J.; Castagnoli, K.; Palmer, S.; Hazelwood, L.; Castagnoli, N. Melatonin fails to protect against long-term MPTPinduced dopamine depletion in mouse striatum. Neurotox. Res., 2000, 1, 261-269.

[115] Lin, C.-H.; Huang, J.-Y.; Ching, C.-H.; Chuang, J.-I. Melatonin reduces the neuronal loss, downregulation of dopamine transporter, and upregulation of D2 receptor in rotenone-induced parkinsonian rats. J. Pineal Res., 2008, 44, 205-213.

[116] Mayo, J.C.; Sainz, R.M.; Tan, D.-X.; Antolín, I.; Rodríguez, C.; Reiter, R.J. Melatonin and Parkinson's disease. Endocrine, 2005, 27, 169-178.

[117] Shaw, K.M.; Stern, G.M.; Sandler, M. Melatonin and parkinsonism. Lancet, 1973, 1, 271.

[118] Dowling, G.A.; Mastick, J.; Colling, E.; Carter, J.H.; Singer, C.M.; Aminoff, M.J. Melatonin for sleep disturbances in Parkinson's disease. Sleep Med., 2005, 6, 459-466.

[119] Medeiros, C.A.M.; Carvalhedo de Bruin, P.F.; Lopes, L.A.; Magalhães, M. C.; de Lourdes Seabra, M.; de Bruin, V.M.S. Effect of exogenous melatonin on sleep and motor dysfunction in Parkinson's disease. A randomized, double blind, placebocontrolled study. J. Neurol., 2007, 254, 459-464.

[120] Fredholm, B.B.; B $\backslash$ ättig, K.; Holmén, J.; Nehlig, A.; Zvartau, E.E. Actions of caffeine in the brain with special reference to factors that contribute to its widespread use. Pharmacol. Rev., 1999, 51, 83 .

[121] Benedetti, M.D.; Bower, J.H.; Maraganore, D.M.; McDonnell, S.K.; Peterson, B.J.; Ahlskog, J.E.; Schaid, D.J.; Rocca, W.A. Smoking, alcohol, and coffee consumption preceding Parkinson's disease: a case-control study. Neurology, 2000, 55, 1350-1358.

[122] Ascherio, A.; Zhang, S.M.; Hernán, M.A.; Kawachi, I.; Colditz, G.A.; Speizer, F.E.; Willett, W.C. Prospective study of caffeine consumption and risk of Parkinson's disease in men and women. Ann. Neurol., 2001, 50, 56-63.

[123] Ross, G.W.; Abbott, R.D.; Petrovitch, H.; Morens, D.M.; Grandinetti, A.; Tung, K.H.; Tanner, C.M.; Masaki, K.H.; Blanchette, P.L.; Curb, J.D. Association of coffee and caffeine intake with the risk of Parkinson disease. JAMA, 2000, 283, 2674

[124] Aguiar, L.M.V.; Nobre, H.V.; Macêdo, D.S.; Oliveira, A.A.; Freitas, R.M.; Vasconcelos, S. M.; Cunha, G. M. A.; Sousa, F. C. F.; Viana, G. S. B. Neuroprotective effects of caffeine in the model of 6-hydroxydopamine lesion in rats. Pharmacol. Biochem. Behav., 2006, 84, 415-419.

[125] Chen, J.F.; Xu, K.; Petzer, J.P.; Staal, R.; Xu, Y.H.; Beilstein, M.; Sonsalla, P.K.; Castagnoli, K.; Castagnoli, N.; Schwarzschild, M.A. Neuroprotection by caffeine and $\mathrm{A}(2 \mathrm{~A})$ adenosine receptor 
inactivation in a model of Parkinson's disease. J. Neurosci, 2001, 21, RC143.

[126] Joghataie, M.T.; Roghani, M.; Negahdar, F.; Hashemi, L. Protective effect of caffeine against neurodegeneration in a model of Parkinson's disease in rat: behavioral and histochemical evidence. Parkinsonism Relat. Disord., 2004, 10, 465-468.

[127] Kachroo, A.; Irizarry, M.C.; Schwarzschild, M.A. Caffeine protects against combined paraquat and maneb-induced dopaminergic neuron degeneration. Exp. Neurol., 2010, 223, 657-661.

[128] Singh, S.; Singh, K.; Gupta, S.P.; Patel, D.K.; Singh, V.K.; Singh, R.K.; Singh, M.P. Effect of caffeine on the expression of cytochrome P450 1A2, adenosine A2A receptor and dopamine transporter in control and 1-methyl 4-phenyl 1, 2, 3, 6tetrahydropyridine treated mouse striatum. Brain Res., 2009, 1283, 115-126.

[129] Xu, K.; Xu, Y.-H.; Chen, J.-F.; Schwarzschild, M.A. Neuroprotection by caffeine: time course and role of its metabolites in the MPTP model of Parkinson's disease. Neuroscience, 2010, $167,475-481$

[130] Xu, K.; Xu, Y.; Brown-Jermyn, D.; Chen, J.-F.; Ascherio, A.; Dluzen, D.E.; Schwarzschild, M.A. Estrogen prevents neuroprotection by caffeine in the mouse 1-methyl-4-phenyl1,2,3,6-tetrahydropyridine model of Parkinson's disease. $J$. Neurosci., 2006, 26, 535-541.

[131] Xu, K.; Xu, Y.-H.; Chen, J.-F.; Schwarzschild, M.A. Caffeine's neuroprotection against 1-methyl-4-phenyl-1,2,3,6tetrahydropyridine toxicity shows no tolerance to chronic caffeine administration in mice. Neurosci. Lett., 2002, 322, 13-16.

[132] Araki, T.; Muramatsu, Y.; Tanaka, K.; Matsubara, M.; Imai, Y. Riluzole (2-amino-6-trifluoromethoxy benzothiazole) attenuates MPTP (1-methyl-4-phenyl-1,2,3,6-tetrahydropyridine) neurotoxicity in mice. Neurosci. Lett., 2001, 312, 50-54.

[133] Jones-Humble, S.A.; Morgan, P.F.; Cooper, B.R. The novel anticonvulsant lamotrigine prevents dopamine depletion in C57 black mice in the MPTP animal model of Parkinson's disease. Life Sci., 1994, 54, 245-252.

[134] Boireau, A.; Dubédat, P.; Bordier, F.; Peny, C.; Miquet, J.M.; Durand, G.; Meunier, M.; Doble, A. Riluzole and experimental parkinsonism: antagonism of MPTP-induced decrease in central dopamine levels in mice. Neuroreport, 1994, 5, 2657-2660

[135] Boireau, A.; Miquet, J.M.; Dubédat, P.; Meunier, M.; Doble, A. Riluzole and experimental parkinsonism: partial antagonism of $\mathrm{MPP}(+)$-induced increase in striatal extracellular dopamine in rats in vivo. Neuroreport, 1994, 5, 2157-2160.

[136] Boireau, A.; Dubedat, P.; Bordier, F.; Imperato, A.; Moussaoui, S. The protective effect of riluzole in the MPTP model of Parkinson's disease in mice is not due to a decrease in $\mathrm{MPP}(+)$ accumulation. Neuropharmacology, 2000, 39, 1016-1020.

[137] Barnéoud, P.; Mazadier, M.; Miquet, J.M.; Parmentier, S.; Dubédat, P.; Doble, A.; Boireau, A. Neuroprotective effects of riluzole on a model of Parkinson's disease in the rat. Neuroscience, 1996, 74, 971-983.

[138] Obinu, M.C.; Reibaud, M.; Blanchard, V.; Moussaoui, S.; Imperato, A. Neuroprotective effect of riluzole in a primate model of Parkinson's disease: behavioral and histological evidence. Mov. Disord., 2002, 17, 13-19.

[139] Jankovic, J.; Hunter, C. A double-blind, placebo-controlled and longitudinal study of riluzole in early Parkinson's disease. Parkinsonism Relat. Disord., 2002, 8, 271-276.

[140] Braz, C. A.; Borges, V.; Ferraz, H. B. Effect of riluzole on dyskinesia and duration of the on state in Parkinson disease patients: a double-blind, placebo-controlled pilot study. Clin. Neuropharmacol., 2004, 27, 25-29.

[141] Cleren, C.; Yang, L.; Lorenzo, B.; Calingasan, N.Y.; Schomer, A.; Sireci, A.; Wille, E.J.; Beal, M.F. Therapeutic effects of coenzyme Q10 (CoQ10) and reduced CoQ10 in the MPTP model of Parkinsonism. J. Neurochem., 2008, 104, 1613-1621.

[142] Horvath, T.L.; Diano, S.; Leranth, C.; Garcia-Segura, L.M.; Cowley, M.A.; Shanabrough, M.; Elsworth, J.D.; Sotonyi, P.; Roth, R.H.; Dietrich, E.H.; Matthews, R.T.; Barnstable, C.J.; Redmond, D.E. Coenzyme Q induces nigral mitochondrial uncoupling and prevents dopamine cell loss in a primate model of Parkinson's disease. Endocrinology, 2003, 144, 2757-2760.

[143] Schulz, J.B.; Henshaw, D.R.; Matthews, R.T.; Beal, M.F. Coenzyme Q10 and nicotinamide and a free radical spin trap protect against MPTP neurotoxicity. Exp. Neurol., 1995, 132, 279283.

[144] Beal, M.F.; Matthews, R.T.; Tieleman, A.; Shults, C.W. Coenzyme Q10 attenuates the 1-methyl-4-phenyl-1,2,3,tetrahydropyridine (MPTP) induced loss of striatal dopamine and dopaminergic axons in aged mice. Brain Res., 1998, 783, 109-114.

[145] Yang, L.; Calingasan, N.Y.; Wille, E.J.; Cormier, K.; Smith, K.; Ferrante, R.J.; Beal, M.F. Combination therapy with coenzyme Q10 and creatine produces additive neuroprotective effects in models of Parkinson's and Huntington's diseases. J. Neurochem. 2009, 109, 1427-1439.

[146] Abdin, A. A.; Hamouda, H. E. Mechanism of the neuroprotective role of coenzyme Q10 with or without L-dopa in rotenone-induced parkinsonism. Neuropharmacology, 2008, 55, 1340-1346.

[147] Somayajulu-Niţu, M.; Sandhu, J.K.; Cohen, J.; Sikorska, M.; Sridhar, T.S.; Matei, A.; Borowy-Borowski, H.; Pandey, S. Paraquat induces oxidative stress, neuronal loss in substantia nigra region and parkinsonism in adult rats: neuroprotection and amelioration of symptoms by water-soluble formulation of coenzyme Q10. BMC Neurosci., 2009, 10,88.

[148] Strijks, E.; Kremer, H.P.; Horstink, M.W. Q10 therapy in patients with idiopathic Parkinson's disease. Mol. Aspects Med., 1997, 18 Suppl, S237-240.

[149] Shults, C.W.; Oakes, D.; Kieburtz, K.; Beal, M.F.; Haas, R.; Plumb, S.; Juncos, J.L.; Nutt, J.; Shoulson, I.; Carter, J.; Kompoliti, K.; Perlmutter, J.S.; Reich, S.; Stern, M.; Watts, R.L.; Kurlan, R.; Molho, E.; Harrison, M.; Lew, M. Effects of coenzyme Q10 in early Parkinson disease: evidence of slowing of the functional decline. Arch. Neurol., 2002, 59, 1541-1550.

[150] Müller, T.; Büttner, T.; Gholipour, A.F.; Kuhn, W. Coenzyme Q10 supplementation provides mild symptomatic benefit in patients with Parkinson's disease. Neurosci. Lett., 2003, 341, 201-204.

[151] Shults, C.W.; Flint Beal, M.; Song, D.; Fontaine, D. Pilot trial of high dosages of coenzyme Q10 in patients with Parkinson's disease. Exp. Neurol., 2004, 188, 491-494.

[152] Storch, A.; Jost, W.H.; Vieregge, P.; Spiegel, J.; Greulich, W.; Durner, J.; Müller, T.; Kupsch, A.; Henningsen, H.; Oertel, W.H.; Fuchs, G.; Kuhn, W.; Niklowitz, P.; Koch, R.; Herting, B.; Reichmann, H. Randomized, double-blind, placebo-controlled trial on symptomatic effects of coenzyme Q(10) in Parkinson disease. Arch. Neurol., 2007, 64, 938-944.

[153] NINDS NET-PD Investigators A randomized clinical trial of coenzyme Q10 and GPI-1485 in early Parkinson disease. Neurology, 2007, 68, 20-28.

[154] Parashos, S.A.; Swearingen, C.J.; Biglan, K.M.; Bodis-Wollner, I.; Liang, G.S.; Ross, G.W.; Tilley, B.C.; Shulman, L.M. Determinants of the timing of symptomatic treatment in early Parkinson disease: The National Institutes of Health Exploratory Trials in Parkinson Disease (NET-PD) Experience. Arch. Neurol., 2009, 66, 1099-1104.

[155] Khuwaja, G.; Khan, M.M.; Ishrat, T.; Ahmad, A.; Raza, S.S.; Ashafaq, M.; Javed, H.; Khan, M.B.; Khan, A.; Vaibhav, K.; Safhi, M.M.; Islam, F. Neuroprotective effects of curcumin on 6hydroxydopamine-induced Parkinsonism in rats: behavioral, neurochemical and immunohistochemical studies. Brain Res., 2011, 1368, 254-263.

[156] Rajeswari, A. Curcumin protects mouse brain from oxidative stress caused by 1-methyl-4-phenyl-1,2,3,6-tetrahydropyridine. Eur. Rev. Med. Pharmacol. Sci., 2006, 10, 157-161.

[157] Rajeswari, A.; Sabesan, M. Inhibition of monoamine oxidase-B by the polyphenolic compound, curcumin and its metabolite tetrahydrocurcumin, in a model of Parkinson's disease induced by MPTP neurodegeneration in mice. Inflammopharmacology, 2008, 16, 96-99.

[158] Vajragupta, O.; Boonchoong, P.; Watanabe, H.; Tohda, M.; Kummasud, N.; Sumanont, Y. Manganese complexes of curcumin and its derivatives: evaluation for the radical scavenging ability and neuroprotective activity. Free Radic. Biol. Med., 2003, 35, 16321644

[159] Yu, S.; Zheng, W.; Xin, N.; Chi, Z.-H.; Wang, N.-Q.; Nie, Y.-X.; Feng, W.-Y.; Wang, Z.-Y. Curcumin prevents dopaminergic neuronal death through inhibition of the c-Jun N-terminal kinase pathway. Rejuvenation Res., 2010, 13, 55-64.

[160] Zbarsky, V.; Datla, K.P.; Parkar, S.; Rai, D.K.; Aruoma, O.I.; Dexter, D.T. Neuroprotective properties of the natural phenolic antioxidants curcumin and naringenin but not quercetin and fisetin 
in a 6-OHDA model of Parkinson's disease. Free Radic. Res., 2005, 39, 1119-1125.

[161] Aubin, N.; Curet, O.; Deffois, A.; Carter, C. Aspirin and salicylate protect against MPTP-induced dopamine depletion in mice. $J$. Neurochem., 1998, 71, 1635-1642.

[162] Di Matteo, V.; Pierucci, M.; Di Giovanni, G.; Di Santo, A.; Poggi, A.; Benigno, A.; Esposito, E. Aspirin protects striatal dopaminergic neurons from neurotoxin-induced degeneration: an in vivo microdialysis study. Brain Res., 2006, 1095, 167-177.

[163] Gören, B.; Mimbay, Z.; Bilici, N.; Zarifoğlu, M.; Oğul, E.; Korfali, E. Investigation of neuroprotective effects of cyclooxygenase inhibitors in the 6-hydroxydopamine induced rat Parkinson model. Turk. Neurosurg., 2009, 19, 230-236.

[164] Maharaj, D.S.; Saravanan, K.S.; Maharaj, H.; Mohanakumar, K.P.; Daya, S. Acetaminophen and aspirin inhibit superoxide anion generation and lipid peroxidation, and protect against 1-methyl-4phenyl pyridinium-induced dopaminergic neurotoxicity in rats. Neurochem. Int., 2004, 44, 355-360.

[165] Maharaj, H.; Maharaj, D.S.; Daya, S. Acetylsalicylic acid and acetaminophen protect against MPP+-induced mitochondrial damage and superoxide anion generation. Life Sci., 2006, 78, 24382443.

[166] Teismann, P.; Ferger, B. Inhibition of the cyclooxygenase isoenzymes COX-1 and COX-2 provide neuroprotection in the MPTP-mouse model of Parkinson's disease. Synapse, 2001, 39, $167-174$.

[167] Gagne, J.J.; Power, M.C. Anti-inflammatory drugs and risk of Parkinson disease: a meta-analysis. Neurology, 2010, 74, 995-1002.

[168] Hu, G.; Bidel, S.; Jousilahti, P.; Antikainen, R.; Tuomilehto, J. Coffee and tea consumption and the risk of Parkinson's disease. Mov. Disord., 2007, 22, 2242-2248.

[169] Tan, L.C.; Koh, W.-P.; Yuan, J.-M.; Wang, R.; Au, W.-L.; Tan, J.H.; Tan, E.-K.; Yu, M.C. Differential effects of black versus green tea on risk of Parkinson's disease in the Singapore Chinese Health Study. Am. J. Epidemiol., 2008, 167, 553-560.

[170] Choi, J.-Y.; Park, C.-S.; Kim, D.-J.; Cho, M.-H.; Jin, B.-K.; Pie, J.E.; Chung, W.-G. Prevention of nitric oxide-mediated 1-methyl-4phenyl-1,2,3,6-tetrahydropyridine-induced Parkinson's disease in mice by tea phenolic epigallocatechin 3-gallate. Neurotoxicology, 2002, 23, 367-374.

[171] Leaver, K.R.; Allbutt, H.N.; Creber, N.J.; Kassiou, M.; Henderson, J.M. Oral pre-treatment with epigallocatechin gallate in 6-OHDA lesioned rats produces subtle symptomatic relief but not neuroprotection. Brain Res. Bull., 2009, 80, 397-402.

[172] Levites, Y.; Weinreb, O.; Maor, G.; Youdim, M.B.; Mandel, S. Green tea polyphenol (-)-epigallocatechin-3-gallate prevents Nmethyl-4-phenyl-1,2,3,6-tetrahydropyridine-induced dopaminergic neurodegeneration. J. Neurochem., 2001, 78, 1073-1082.
[173] Reznichenko, L.; Kalfon, L.; Amit, T.; Youdim, M.B.H.; Mandel, S.A. Low dosage of Rasagiline and epigallocatechin gallate synergistically restored the nigrostriatal axis in MPTP-induced parkinsonism. Neurodegener. Dis., 2010, 7, 219-231.

[174] Blanchet, J.; Longpré, F.; Bureau, G.; Morissette, M.; DiPaolo, T.; Bronchti, G.; Martinoli, M.-G. Resveratrol, a red wine polyphenol, protects dopaminergic neurons in MPTP-treated mice. Prog. Neuropsychopharmacol. Biol. Psychiatry., 2008, 32, 1243-1250.

[175] Lu, K.-T.; Ko, M.-C.; Chen, B.-Y.; Huang, J.-C.; Hsieh, C.-W.; Lee, M.-C.; Chiou, R.Y.Y.; Wung, B.-S.; Peng, C.-H.; Yang, Y.-L. Neuroprotective effects of resveratrol on MPTP-induced neuron loss mediated by free radical scavenging. J. Agric. Food Chem., 2008, 56, 6910-6913.

[176] Jin, F.; Wu, Q.; Lu, Y.-F.; Gong, Q.-H.; Shi, J.-S. Neuroprotective effect of resveratrol on 6-OHDA-induced Parkinson's disease in rats. Eur. J. Pharmacol., 2008, 600, 78-82.

[177] Khan, M.; Ahmad, A.; Ishrat, T.; Khan, M.B.; Hoda, M.N.; Khuwaja, G.; Raza, S.S.; Khan, A.; Javed, H.; Vaibhav, K.; Islam, F. Resveratrol attenuates 6-hydroxydopamine-induced oxidative damage and dopamine depletion in rat model of Parkinson's disease. Brain Res., 2010, 1328, 139-151.

[178] Bové, J.; Prou, D.; Perier, C.; Przedborski, S. Toxin-induced models of Parkinson's disease. NeuroRx, 2005, 2, 484-494.

[179] Walle, T. Bioavailability of resveratrol. Ann. N. Y. Acad. Sci., 2011, 1215, 9-15.

[180] Bhagavan, H.N.; Chopra, R.K. Coenzyme Q10: absorption, tissue uptake, metabolism and pharmacokinetics. Free Radic. Res., 2006 , 40, 445-453.

[181] Anand, P.; Kunnumakkara, A.B.; Newman, R.A.; Aggarwal, B.B Bioavailability of curcumin: problems and promises. Mol. Pharm., 2007, 4, 807-818.

[182] Lee, M.-J.; Maliakal, P.; Chen, L.; Meng, X.; Bondoc, F.Y.; Prabhu, S.; Lambert, G.; Mohr, S.; Yang, C.S. Pharmacokinetics of tea catechins after ingestion of green tea and (-)-epigallocatechin-3gallate by humans: formation of different metabolites and individual variability. Cancer Epidemiol. Biomark. Prev., 2002, 11, 1025-1032.

[183] Amri, A.; Chaumeil, J.C.; Sfar, S.; Charrueau, C. Administration of resveratrol: What formulation solutions to bioavailability limitations? J. Control Release, 2011, 58, 182-193.

[184] Mandel, S.; Grünblatt, E.; Riederer, P.; Gerlach, M.; Levites, Y; Youdim, M.B.H. Neuroprotective strategies in Parkinson's disease : an update on progress. CNS Drugs, 2003, 17, 729-762.

[185] Simola, N.; Morelli, M.; Pinna, A. Adenosine A2A receptor antagonists and Parkinson's disease: state of the art and future directions. Curr. Pharm. Des., 2008, 14, 1475-1489. 